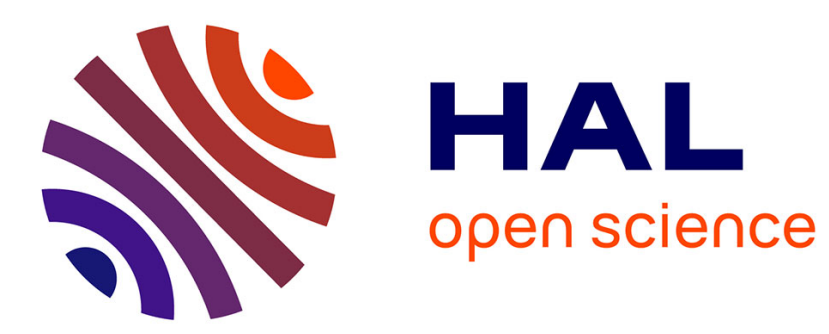

\title{
Characterisation and replication of metallic micro-fluidic devices using three different powders processed by hot embossing
}

\author{
Mohamed Lakdhar Sahli, Jean-Claude Gelin, Thierry Barrière
}

\section{To cite this version:}

Mohamed Lakdhar Sahli, Jean-Claude Gelin, Thierry Barrière. Characterisation and replication of metallic micro-fluidic devices using three different powders processed by hot embossing. Powder Technology, 2013, 246, pp.284 - 302. 10.1016/j.powtec.2013.05.026 . hal-00982815

\section{HAL Id: hal-00982815 https://hal.science/hal-00982815}

Submitted on 24 Apr 2014

HAL is a multi-disciplinary open access archive for the deposit and dissemination of scientific research documents, whether they are published or not. The documents may come from teaching and research institutions in France or abroad, or from public or private research centers.
L'archive ouverte pluridisciplinaire HAL, est destinée au dépôt et à la diffusion de documents scientifiques de niveau recherche, publiés ou non, émanant des établissements d'enseignement et de recherche français ou étrangers, des laboratoires publics ou privés. 


\title{
Characterisation and replication of metallic micro-fluidic devices using three different powders processed by hot embossing
}

\author{
M. Sahli", J-C Gelin and T. Barriere \\ Femto-ST Institute, Applied Mechanics Dept., CNRS UMR 6174, ENSMM, 25030 Besançon cedex, France. \\ Mohamed.Sahli@ens2m.fr
}

\section{INTRODUCTION}

In recent years, the miniaturisation and manufacturing of micro-components have gained increasing attention in both industry and academia [1-4]. The microinjection moulding process is rapidly becoming one of the most promising fabrication technologies for the mass production of thermoplastic polymer micro-parts [5-7]. Most of the applications are concentrated in the fields of micro-optics, micro-fluidics and medical instruments. Hot embossing is also a manufacturing method used for the fabrication of polymer-based microcomponents. It provides several advantages, such as low-cost moulds, high replication accuracy for micro-feature generation and ease of operation [8, 9]. For these reasons, manufacturing by hot-embossing $[10,11]$ rather than injection moulding is advantageous. It also introduces less residual stress into the polymer because the polymer chains must stretch and flow only a very short distance from the substrate into the patterned microstructure during hot-embossing. Additionally, the temperature variation range for the polymer is smaller than that required in injection moulding, which leads to reductions in both the shrinkage that occurs during cooling and the frictional forces that act on the micro-features during demoulding [12-16].

Conventionally, the mould tooling is made of either steel or aluminium and can be manufactured by Computer Numerical Control machining (CNC) and Electric discharge machining (EDM); after it is manufactured, the mould can be used to produce polymer microparts via either hot embossing or injection moulding $[17,18]$. The surface quality of the mould is highly dependent on the cutting conditions used during machining, which significantly influence the resulting surface roughness [19, 20]. For example, in micro-fluidic systems, these techniques generate tools with a high surface roughness and micro-channels that generate a reduction in the overall efficiency of fluidic flow. In this study, to establish the basis of micro-pattern manufacturing of the metallic tool using the hot embossing process, an alternative method was applied to form micro-channels in the metallic moulds with a low surface roughness. The micro-fluidic chip developed here is used as an example to discuss the use of various mould insert materials by hot embossing.

Various investigations have been conducted concerning the influence of both the physical and processing parameters, such as the particle size and solid loading of the powder in the mixture, the effect of sintering temperature on the control and dimensional changes, the density, mechanical properties and roughness surfaces of the components, have received increasing attention in recent years [21]. German et al. [22] investigated the effect of solid loading on the dimensional change that occurs during solvent debinding of the injection moulded components. Liu et al. [23] investigated the effects of solid loading and extrusion on mixing and feedstock homogeneity for the injection moulding of micro-structured components. The results demonstrated that $316 \mathrm{~L}$ stainless steel feedstock with a suitable solid loading (equal to 58 vol. \%) can be successfully used for the forming of micro-structured parts with proper shape retention. The micro-structured parts exhibit the necessary strength for demoulding with no observable debinding defects and a final sintered microstructure characterised by shape retention.

Recently, Tay et al. [24] have succeeded in the manufacturing of micro-gears using the micro-powder injection moulding process with $316 \mathrm{~L}$ stainless steel powder possessing 
particle sizes of $2.4 \mu \mathrm{m}$ and a multi-component wax-based binder system. The analysis revealed different grain structures at the tooth $(\approx 35 \mu \mathrm{m})$ and hub of the micro-gear $(\approx 5 \mu \mathrm{m})$. Significant grain growth was also observed at the tooth. Meng et al. [25] conducted an experimental analysis on the replication of a micro-fluidic system by micro-powder injection moulding using 316L stainless steel. Additionally, they also investigated the dimensional change and surface roughness of the micro-mixer. They obtained proper replication with appropriate shape retention lacking in visible defects by use of a powder injection moulding process with a $316 \mathrm{~L}$ stainless steel feedstock. The dimensional shrinkage of the micro-mixer occurred mainly in the sintering step, whilst the dimensional change was not noticeable in the debinding step. The surface topography of the silicon mould insert was properly replicated in the stainless steel micro-mixer. Fu et al. [26] investigated the manufacturing of a $316 \mathrm{~L}$ stainless steel cylindrical micro-structure array using a silicon mould insert with the hot embossing process. Their results demonstrated the effects of various embossing parameters on the filling of micro-cavities in the silicon mould insert and the de-moulding of microstructures. This study was only focused on the replication of a micro-structured array with an aspect ratio of 2. It was limited to the use of 316L stainless steel with unknown solid loading and binder percentages in its feedstock. Most of the work up to date on hot embossing focused on to use this process as a flexible, low-cost micro-fabrication method for polymer microstructures over large surface areas. To date our work was focused on the use of the hot embossing process adapted to metal powders for the manufacturing of a micro-fluidic die mould with low surface roughness. An integrated rapid prototyping chain was established for rapid manufacturing of the micro-structured master in metallic powders made from elastomeric moulds by use of the hot embossing process. This rapid manufacturing chain, offers a rapid and flexible manufacturing route for fabrication of prototype micro devices from polymer solutions. This study uses the lithography technology to fabricate the silicon mould insert with nanoscale details and surface roughness at a lower cost. Due to the mechanical strength limitation, silicon material is usually not suitable to use as mould material. In this study, the silicon master was used for casting of silicone to fabricate elastomeric micro-fluidic mould. The choice to use a flexible mould was related to the demoulding facilities for the micro-structures and the increase of lifetime of the mould when used in the hot embossing process.

This paper describes the elaboration and characterisation of different feedstocks for use in metallic hot embossing and the manufacture of micro-structures with low surface roughness. In the experimental tests presented here, only the temperature and pressure were considered while analysing the manner in which the metallic die master can be archived with the highest replication accuracy. These experiments allow us to understand and qualify the influence of hot embossing processing conditions on the geometrical embossed accuracy of the replicas and the mechanical properties of the final components after solid state sintering. The sintering stage was carried out in vacuum using the metallic micro-structured samples obtained at different solid loadings. Therefore, the present work also analysed the shrinkages, densities, Vickers hardness values and roughness variations of the micro-fluidic specimens using three shades.

\section{EXPERIMENTAL MATERIALS AND METHODS}

\subsection{MATERIALS}

Fine powders of 316L stainless steel were used to develop the mixtures dedicated to the hot embossing process. The powder particulates had a spherical shape and an average particle size of $5 \mu \mathrm{m}-80 \%$. This shape is generally more appropriate for obtaining a feedstock with low viscosity. The powders had a density equal to $7.9 \mathrm{~g} . \mathrm{cm}^{-3}$ and were provided by Sandvik Osprey Company. Figure 1 gives a photograph of the 316L stainless steel powder particle distribution. 
The micron-size pre-alloyed powder (Fe-Ni $8 \%$ ) was composed of PA-FN08 and cobalt tungsten carbide with $19.9 \%$ WC (Co-WC). The ME1107 powders were characterised to have an average particle size of $5 \mu \mathrm{m}$. The powders were provided by Eurotungstene Company ${ }^{\circledR}$ (Eramet) with densities equal to 7.93 and 9.74 g. $\mathrm{cm}^{-3}$, respectively. The powder morphology is given in Fig. 2. Before mixing, the powders were dried in a vacuum oven at a temperature of $120^{\circ} \mathrm{C}$ for $5 \mathrm{~h}$ to remove any moisture.

Feedstocks of Co-WC, Fe-Ni 8\% and 316L stainless steel based on 40 to $75 \%$ solid loadings (by volume) were prepared using a twin-screw mixer. The binder system used in this study consisted of paraffin wax, polypropylene and stearic acid. The composition of the binder corresponded to the ratio of PP:PW:SA given as relative fractions 40:55:5. The characteristics of the different binder systems and the raw powders are related in Tables 1 and 2.

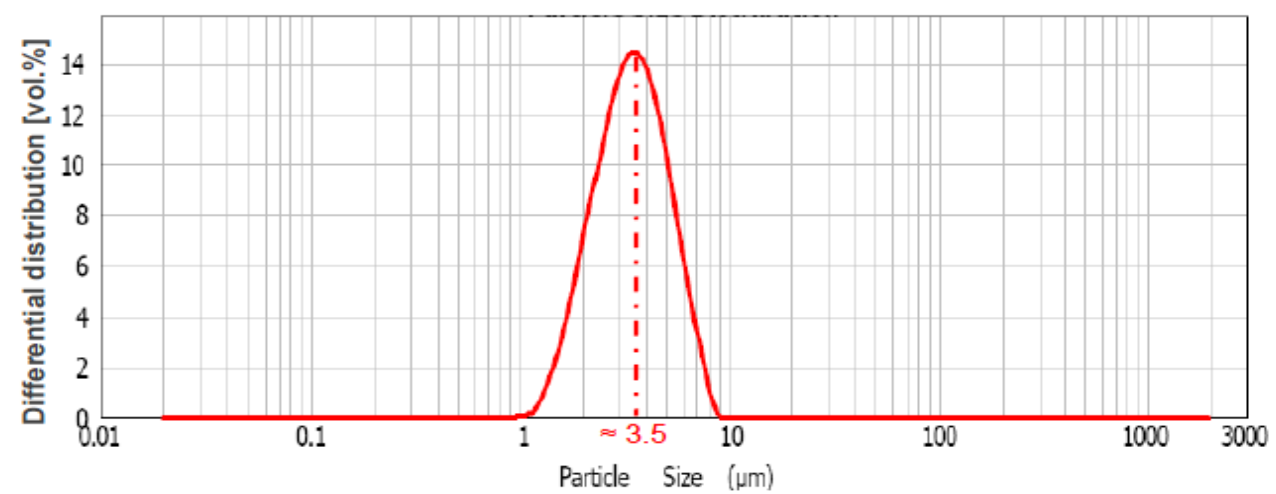

Figure 1. The particle size distribution for the $316 \mathrm{~L}$ stainless steel powder $\left(\mathrm{d}_{50}=3.4 \mu \mathrm{m}\right)$.

Table 1. Characteristics of the three different powders.

\begin{tabular}{|l|c|c|c|c|c|c|}
\hline \multicolumn{7}{|c|}{ Powder size and density } \\
\hline Powder & Particle shape & $\mathbf{d}_{\mathbf{1 0}}(\boldsymbol{\mu \mathbf { m }})$ & $\mathbf{d}_{\mathbf{5 0}}(\boldsymbol{\mu \mathbf { m }})$ & $\mathbf{d}_{\mathbf{9 0}}(\boldsymbol{\mu m})$ & Density $\left(\mathbf{g} / \mathbf{c m}^{\mathbf{3}}\right)$ & Tap density $\left(\mathbf{g} / \mathbf{c m}^{\mathbf{3}}\right)$ \\
\hline Inox 316L & Spherical & 1.80 & 3.40 & 6.0 & 7.90 & 4.60 \\
\hline Fe-Ni 8\% & Irregular & 2.40 & 4.40 & 8.0 & 7.93 & 2.90 \\
\hline Co-WC & Irregular & 2.90 & 6.10 & 11.9 & 9.74 & 2.17 \\
\hline
\end{tabular}

Table 2.Characteristicsof the different binder components

\begin{tabular}{|l|c|c|}
\hline Binders & Density [g.cm & Melting temperature $\left[{ }^{\circ} \mathbf{C}\right]$ \\
\hline Stearic acid (SA) & 0.890 & 70 \\
\hline Paraffin wax (PW) & 0.910 & 60 \\
\hline Polypropylene (PP) & 0.900 & 125 \\
\hline
\end{tabular}
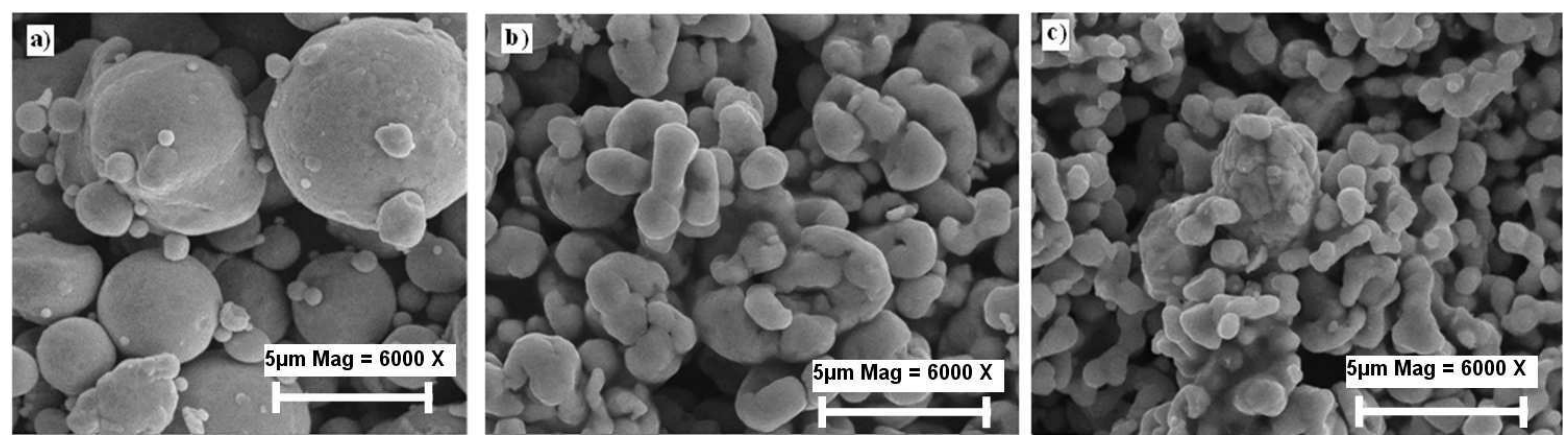

Figure 2. SEM micrographs of the different feedstocks, including (a) the 316L stainless steel powder, (b) FeNi 8 $\%$ and (c) Co-WC. 


\subsection{PROCESSING STEPS}

The main steps of the hot embossing process include the Lithographie, Galvanoformung, Abformung (UV-LIGA) process for the SU-8/Si mould fabrication (the master mould with a thick negative photoresist (SU-8) deposited on large silicone wafer (Si)), elastomeric inverse mould manufacturing using a casting process, the development of metal powder feedstocks for filling the mould, the hot embossing process, and the debinding and sintering stages. The processing stages have been developed for use in the rapid manufacturing of high-quality metallic replicas onto the elastomeric moulds, as illustrated in Fig. 3.

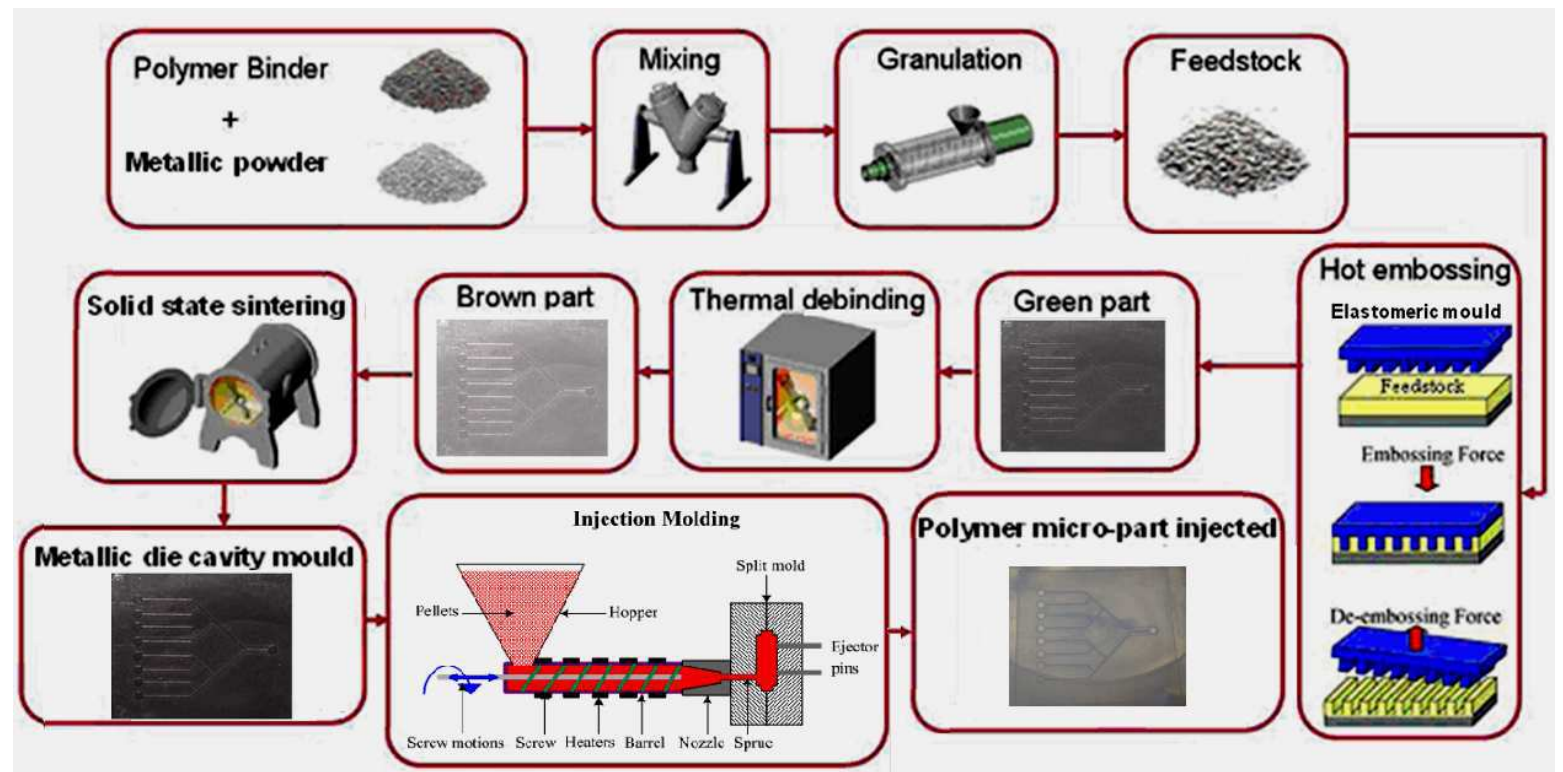

Figure 3. A schematic manufacturing diagram of the powder components developed by rapid prototyping.

\subsubsection{MIXING TESTS}

Experiments related to the mixing of binders and feedstocks were carried out using a twinscrew Brabender ${ }^{\circledR}$ Plastograph EC mixer with a pair of rotor blades. The maximum capacity of the mixing chamber was $55 \mathrm{~cm}^{3}$. The twin-screw mixer was connected with appropriate software to measure the mixing torque; the same processing conditions were used for each mixture, including a mixing temperature of $160{ }^{\circ} \mathrm{C}$, a mixing time equal to $30 \mathrm{~min}$ and a mixing rotation speed of $30 \mathrm{rpm}$. The mixtures were prepared individually with different solid loadings from $40 \%$ up to $75 \%$ with an incremental increase of $5 \%$ for each level.

The powders were loaded when the temperature had stabilised at the required mixing temperature to facilitate homogeneous mixing of the powder and binder components. During a mixing test, the mixture homogeneity can be evaluated through the mixing torque curves. Uniform mixing is achieved when the torque reaches a stable, steady state value. Figure 4 shows Scanning Electron Microscope images (SEM) of the different feedstock powders after the mixing stage. Finally, the feedstocks were granulated into small pellets for rheology characterisation and were used in the hot embossing process for the development of microfluidic replicas. 


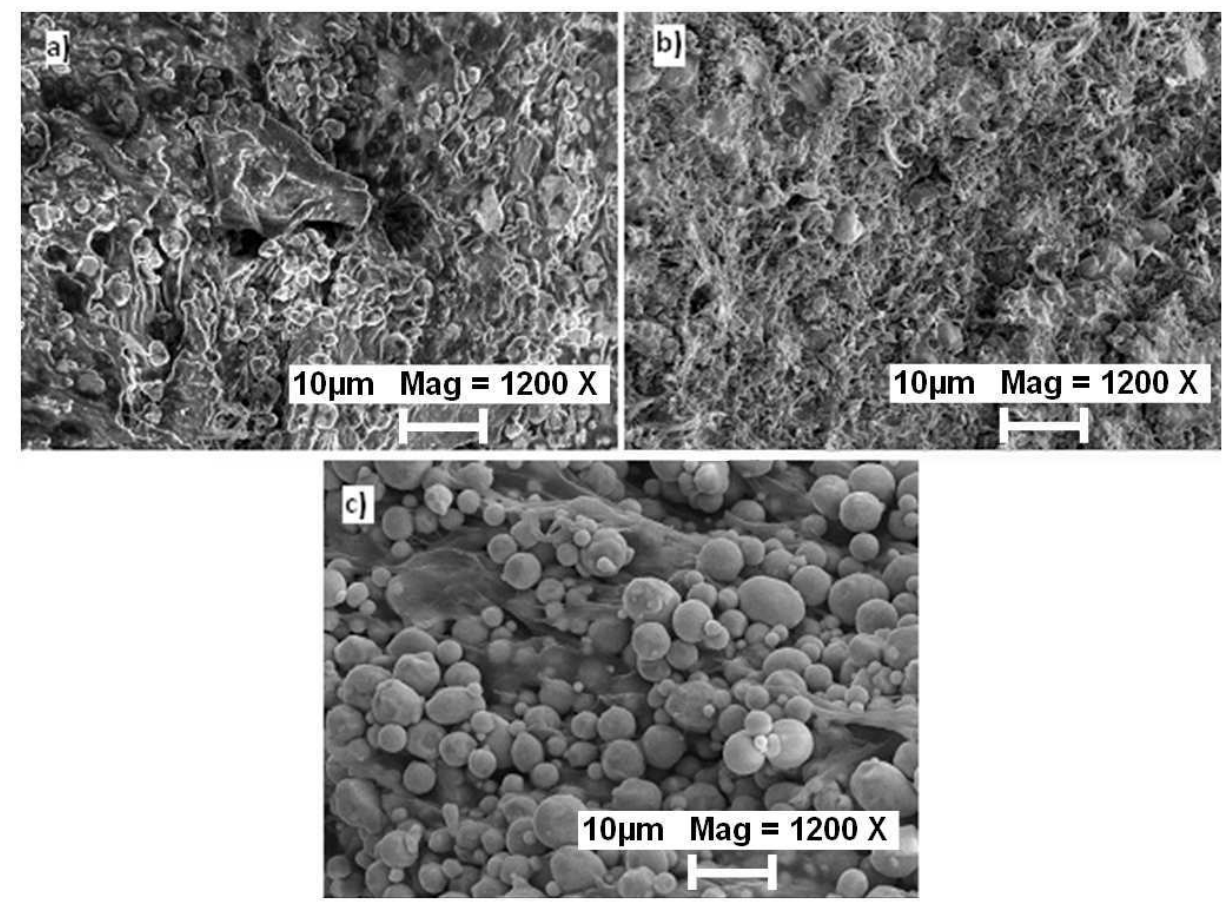

Figure 4. SEM micrographs of the feedstock after mixing, including (a) Fe-Ni $8 \%$ (the solid loading equal to $64 \%$ ), b) Co-WC (the solid loading equal to $44 \%$ ) and (c) 316L (the solid loading equal to $60 \%$ ).

\subsubsection{ELASTOMERIC MICRO-STRUCTURED MOULD}

SU-8 negative photoresist was spin coated onto a clean silicon wafer and exposed by the UV LIGA method to obtain the micro-fluidic system as a micro-mould for casting, which is abbreviated as the SU-8/Si master. Figure 5 presents the SU-8/Si mould insert with the microfluidic structure. The dimensions of a typical micro-fluidic cavity are shown in Fig 6b.The elastomeric die cavity moulds were obtained by casting silicone rubber over the SU-8/Si master, enabling the development of micro-structures with very well defined and smooth sidewalls. The silicone rubber (Sylgard 184) used as the material for the elastomeric moulds was provided by Dow Corning Inc ${ }^{\circledR}$. The silicone base and catalyst were thoroughly mixed a ratio of $1: 10$. The mixture was degassed for approximately $5 \mathrm{~min}$ in a primary vacuum to avoid the trapping of air in the silicone. Next, the silicone mixture was poured over the SU8/Si and cured at $70^{\circ} \mathrm{C}$ for $4 \mathrm{~h}$; after curing, the silicone was easily pealed from the SU$8 / \mathrm{Si}$ master. The elastomeric mould was obtained with one face that contained all of the details of the original master. The manufacturing process details for the fabrication of the SU8/ Si and PDMS moulds is also described in [27-30]. Figs. 5a, 5b and 6a display micrographs of the SU-8/Si master and the negative replicas. Accordingly, the micro-fluidic system was produced with a model that considers subsequent shrinkage during the sintering stage (Fig 6a and $b)$.
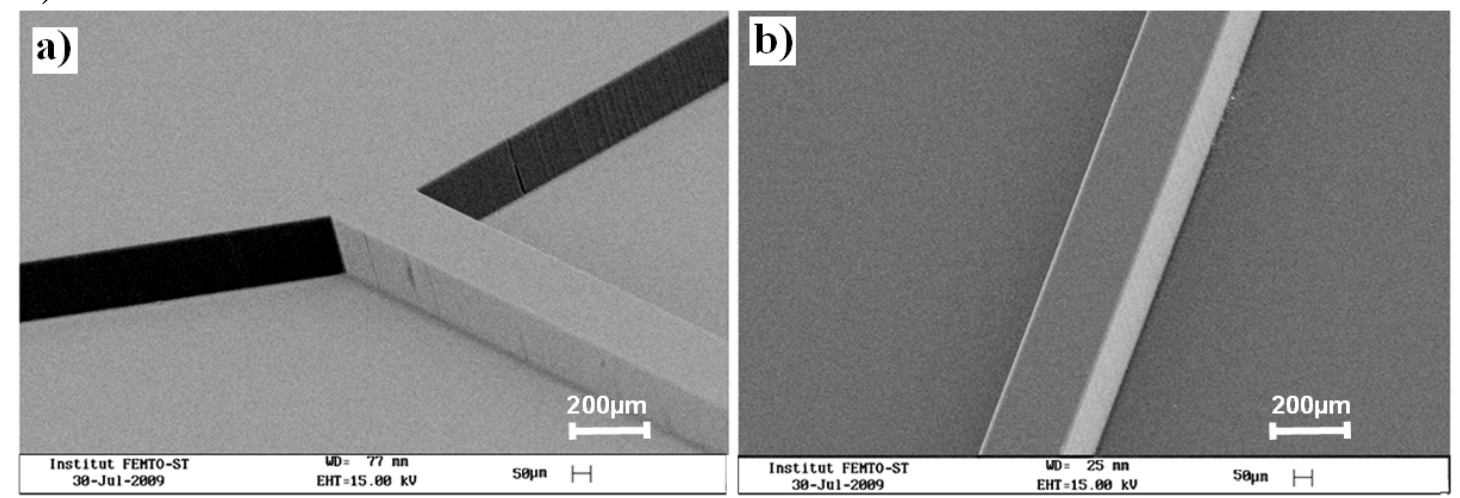

Figure 5. SEM micrographs of the SU-8/Si master mould showing (a) a reservoir and (b) a channel. 

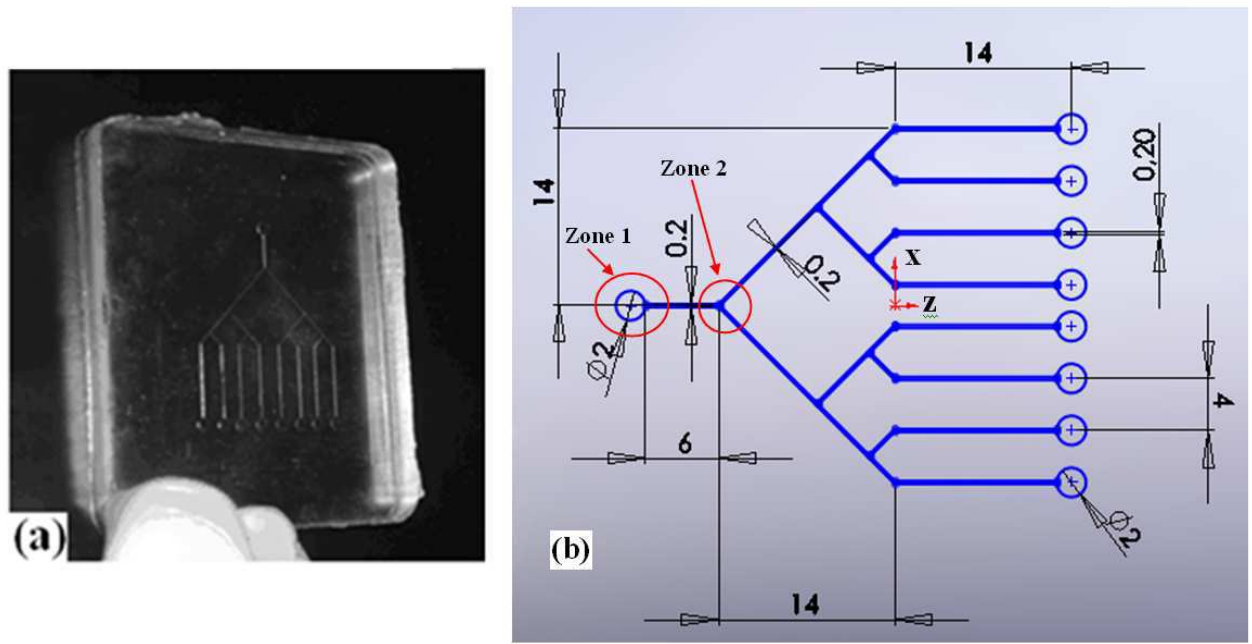

Figure 6. a) Geometry of the patterns of the elastomeric die cavity mould and b) a description of the mould dimensions and micro-fluidic geometries (unit: $\mathrm{mm}$ ).

Scanning mechanical microscopy (SMM) was used to obtain a digital fingerprint corresponding to a portion of the elastomeric die cavity mould manufactured by casting. The fingerprint allows for a description of manufacturing quality and the quantification of geometry as well as the surface, as a part of the intrinsic characteristics of the elastomeric die cavity mould. Both details of interest in the elastomeric die cavity mould developed by casting were obtained with SMM corresponding to the shapes illustrated in Figure 7.

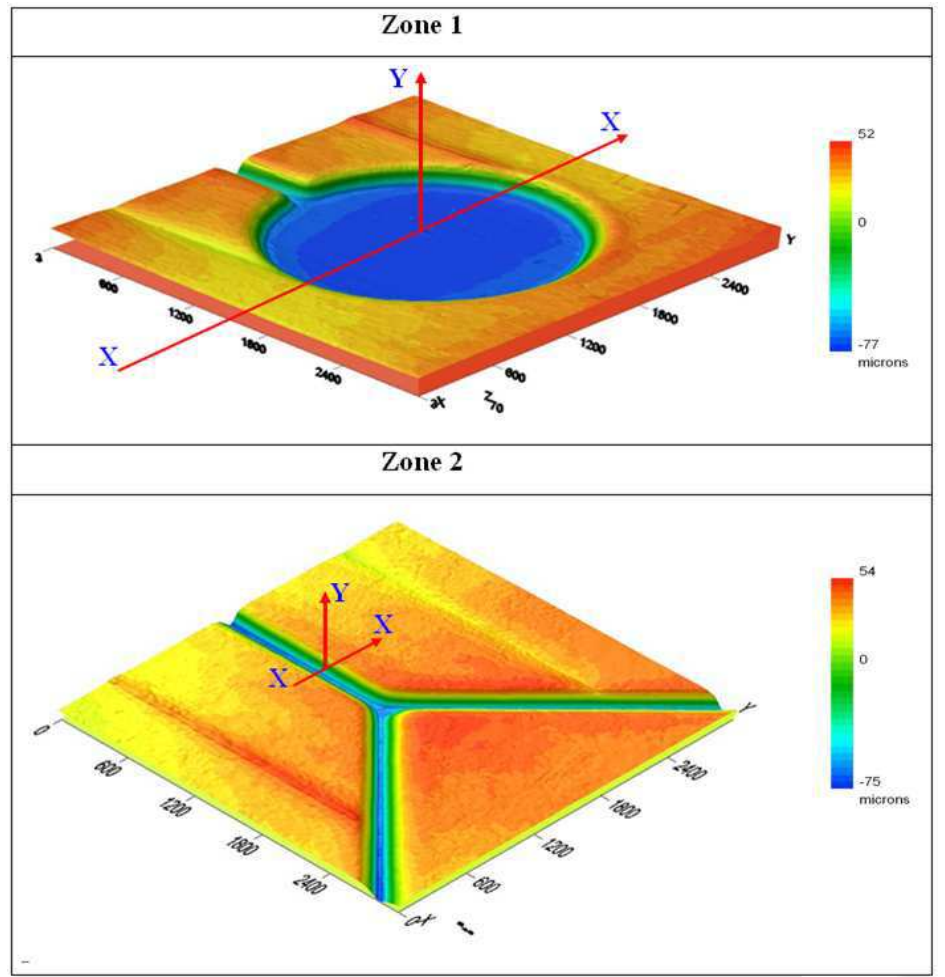

Figure 7. 3D topographic imprints of the elastomeric die cavity mould realised by casting.

\subsubsection{HOT EMBOSSING PROCESS}

The elastomeric die cavity mould was used for the hot embossing process to manufacture micro-components using feedstocks based on polypropylene, paraffin wax and stearic acid. This process involved heating a feedstock to its softening temperature (i.e., just above the 
melting temperature for a semi-crystalline thermoplastic polymer) and then pressing it into an elastomeric mould with applied pressure. Next, the feedstock was cooled down, and the part was demoulded at room temperature. After the cooling stage, the metallic replicas were easily peeled from the elastomeric die cavity mould. The elastomeric die cavity mould was repeatedly used with little degradation. The embossed tests were gradually established and carried out in two different cases. In the first case, the tools were heated at a temperature equal to $170{ }^{\circ} \mathrm{C}$ with a heating rate of $5{ }^{\circ} \mathrm{C} / \mathrm{s}$; additionally, the dwell time was $10 \mathrm{~min}$, and the forming force was varied from 200 to $400 \mathrm{~N}$. In the second case, the tools were heated from room temperature to a temperature in the interval from 130 to $190{ }^{\circ} \mathrm{C}$; the heating rate was 5 ${ }^{\circ} \mathrm{C} / \mathrm{s}$, while the forming force was slowly increased to a load of $400 \mathrm{~N}$. The temperatures were between the highest melting temperature $\mathrm{T}_{\mathrm{f}}\left(\mathrm{T}_{\mathrm{f}_{-} \mathrm{PP}}=125^{\circ} \mathrm{C}\right)$ and the lowest degradation temperature $\mathrm{T}_{\mathrm{d}}\left(\mathrm{T}_{\mathrm{d}-\mathrm{SA}}=200^{\circ} \mathrm{C}\right)$ of the binder system. In both cases, the final qualities of the metallic replicas were measured with SMM to determine the dimensions and surface roughness.

\subsubsection{DEBINDING AND SINTERING STAGES}

The process was comprised of two sequential stages, including thermal debinding followed by solid state sintering. In the thermal debinding stage, the residual binders were converted into gas and eliminated. Then, the powders were sintered, resulting in strengthened green parts capable of yielding products without defects. First, the debinding was performed at $500{ }^{\circ} \mathrm{C}$ in a thermal oven. The defect-free embossed parts were placed on an $\mathrm{Al}_{2} \mathrm{O}_{3}$ plate. The debinding temperature used was based on the TGA curve identified for the binder system. Because the SA and PW finish begin to degrade at approximately $330{ }^{\circ} \mathrm{C}$, the first debinding temperature used was $350{ }^{\circ} \mathrm{C}$. The temperature was then gradually increased to $500{ }^{\circ} \mathrm{C}$, which corresponded to the TGA curve that leads to a significant loss of polypropylene weight and the removal of all residual binder. The debinding was performed in the temperature range between 350 and $500{ }^{\circ} \mathrm{C}$.

In this study, the second stage of the solid state sintering process was conducted in vacuum with graphite heating element furnace offering a maximum temperature of $1900^{\circ} \mathrm{C}$. The samples were maintained at this temperature for $1 \mathrm{~h}$, and then the temperature was increased between $900-1050{ }^{\circ} \mathrm{C}, 1000-1285{ }^{\circ} \mathrm{C}, 1000$ and $1360{ }^{\circ} \mathrm{C}$ a rate of $5{ }^{\circ} \mathrm{C} / \mathrm{min}, 10$ ${ }^{\circ} \mathrm{C} / \mathrm{min}$ or $15{ }^{\circ} \mathrm{C} / \mathrm{min}$ for $\mathrm{Co}-\mathrm{WC}, \mathrm{Fe}-\mathrm{Ni}$ and $316 \mathrm{~L}$, respectively. Table 3 summarises the processes associated with the debinding and sintering stages. Additionally, the same primary vacuum was used during the sintering test.

Table 3. A description of the debinding and sintering treatments used for the different elaborated feedstocks.

\begin{tabular}{|l|l|l|}
\hline Steps & Procedure & \\
\hline \multirow{4}{*}{ 1. Thermal debinding } & $\begin{array}{l}\text { Heating up to } 350^{\circ} \mathrm{C} \\
\left.\text { (heating rate } 10^{\circ} \mathrm{C} / \mathrm{min}\right)\end{array}$ & \\
\cline { 2 - 3 } & Dwelling $(30 \mathrm{~min})$ & \\
\cline { 2 - 3 } & $\begin{array}{l}\text { Heating up to } 500^{\circ} \mathrm{C} \\
\left.\text { (heating rate } 10^{\circ} \mathrm{C} / \mathrm{min}\right)\end{array}$ & \\
\cline { 2 - 3 } 2. Sintering & Dwelling $(30 \mathrm{~min})$ & $\begin{array}{l}\mathrm{T}_{1}[\mathrm{Stainless} \text { steel }]=1000-1360^{\circ} \mathrm{C} \\
\text { (heating up to temperature }\left(\mathrm{T}_{1}\right) \\
\mathrm{T}_{1}[\mathrm{Co}-\mathrm{WC}]=900-1050^{\circ} \mathrm{C} \\
\mathrm{T}_{1}[\mathrm{Fe}-\mathrm{Ni}]=1000-1285^{\circ} \mathrm{C}\end{array}$ \\
\hline & \begin{tabular}{l} 
(heating rate 5 to $\left.15^{\circ} \mathrm{C} / \mathrm{min}\right)$ \\
\cline { 2 - 3 }
\end{tabular} & $\begin{array}{l}\text { Cooling down } \\
\left.\text { (cooling rate } 5^{\circ} \mathrm{C} / \mathrm{min}\right)\end{array}$ \\
\cline { 2 - 3 } & & \\
\hline
\end{tabular}

\subsection{SAMPLE CHARACTERISATION}

\subsubsection{RHEOLOGY CHARACTERISATION AND THE THERMAL DEGRADATION PROPERTIES (TGA)}


The rheological behaviour of the feedstocks was measured using a capillary rheometer provided by Instruments Bohlin ${ }^{\circledR}$. A series of experiments were performed in which the samples were extruded through a die with a $1 \mathrm{~mm}$ diameter and measuring $16 \mathrm{~mm}$ in length. Three temperatures were tested, including 150,170 and $190{ }^{\circ} \mathrm{C}$, beyond the melting temperature of the binder. Shear rates varying from $10^{2}$ to $10^{4} \mathrm{~s}^{-1}$ were applied using the die with the measurements reported above, giving a ratio (L/D) equal to 16 .

The degradation temperature ranges of the binder components in the powder/binder feedstocks were obtained from thermogravimetric analyses (TGA). The analysis results indicated the thermal limitations for the initial processes, including the mixing and hot embossing processes. TGA was performed using a Setaram Setsys analyser ${ }^{\circledR}$.

\subsubsection{ROUGHNESS CHARACTERISATION}

To assess the dimensional and geometrical qualities of the replicas, comparative 2D profile measurements and 3D contours were performed using scanning mechanical microscopy (SMM). The dimensions, the surface roughness and the surface topographies of the elastomeric mould inserts and the micro-fluidic samples were collected using a mechanical profilometer (Tencor-Alpha Step IQ) with a $5 \mu \mathrm{m}$ diamond tip radius operated a scanning speed of $5 \mu \mathrm{m} / \mathrm{s}$ over a length of $1 \mathrm{~mm}$ both inside and outside the reservoir pattern ( $2 \mathrm{~mm}$ in diameter). Scans were collected on both the elastomeric mould insert and the microsystem samples (zone 1, see Fig. 6b). The shrinkage of the micro-fluidic device was determined by the dimensional changes in width and height measured for the micro-sized structures.

\section{RESULTS AND DISCUSSION}

\subsection{Thermal degradation characteristics}

The degradation temperature ranges, as related to the binder components in the powder/binder feedstocks, were obtained by thermogravimetric analyses (TGA), which were performed using a Setaram Setsys analyser ${ }^{\circledR}$. Fig. 8 shows the TGA curves of the multicomponent binder and the individual binder components. In the TG curves collected above 170,250 and $350{ }^{\circ} \mathrm{C}$, the stearic acid, paraffin wax and polypropylene each start to decompose, respectively. Additionally, each degradation temperature range is very broad, and the associated mass percentage loss of each of the three materials tends to $0 \%$ (complete loss) at higher temperatures, which is the ideal case for binder removal in debinding of the Metal Injection Molded (MIM) part.

Similarly, the multi-component binder, which resulted from mixing of the individual binder components, also underwent two distinct degradation steps. Through a comparison of the TGA curves, it is reasonable that the full degradation of PW and SA occurred in the first degradation temperature range $\left(170-330^{\circ} \mathrm{C}\right)$, whereas the degradation of PP took place at the higher temperatures $\left(340-450{ }^{\circ} \mathrm{C}\right)$. Above $450{ }^{\circ} \mathrm{C}$, all of the binder components were burned off. Based on the TGA results, a multi-step debinding profile was established, demonstrating the progressive removal of each of the three binder components. The progressive debinding over a wide temperature range can help to retain the integrity of the micro-structured cavities and prevent the formation of debinding defects, such as cracking and slumping. 


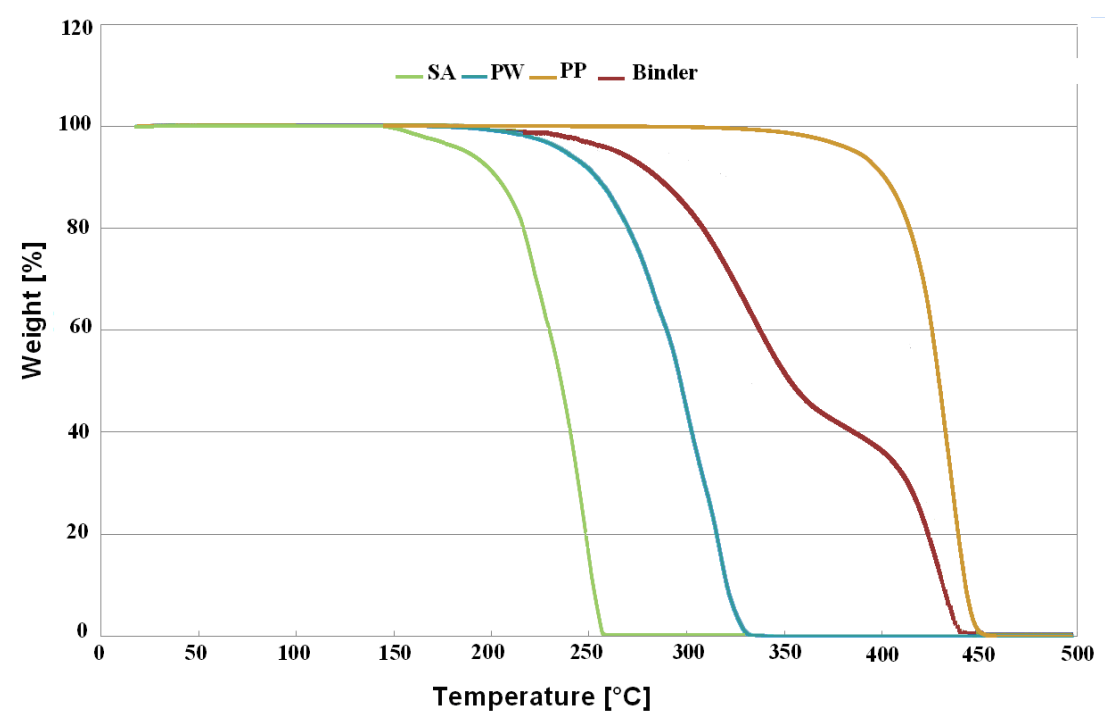

Figure 8. TGA curves of all binders and the combined binder systems (PW $55 \%$, PP $40 \%$, SA $5 \%$ ).

\subsection{PREPARATION AND CHARACTERISATION OF THE FEEDSTOCKS}

Several feedstocks were developed by using different powders indifferent loading ratios (see table 4). The mixing torques were measured and plotted versus times for different $\mathrm{Fe}-\mathrm{Ni}$ $8 \%$ feedstocks in Figure 9. The observed torque peaks are due to the introduction of small amounts of feedstock into the mixture. It should be noted that the mixture with a solid loading of $60 \%$ had the lowest torque homogenisation, reaching a value of approximately 1.5 N.m. Therefore, the optimal load of Fe-Ni powder was identified to be $60 \%$. Beyond a load of 62 $\%$, the feedstock did not demonstrate mixability. Instead, it reached the threshold of mixability, which leads to the formation of an inhomogeneous mixture. During the mixing tests, Co-WC, Fe-Ni and 316L powders were found to be non-mixablefor critical solid loads greater than or equal to 46,62 and $66 \%$, respectively. The following table summarises the results that were obtained for the different powder mixing experiments.

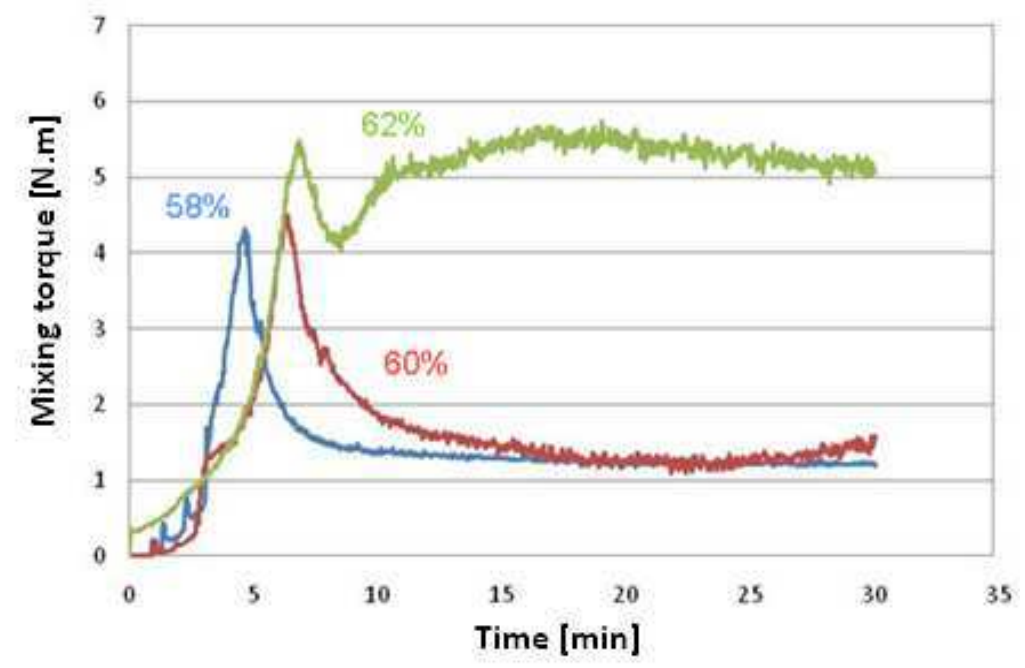

Figure 9. Mixing torque vs. time for three different solid loadings corresponding to three different Fe-Ni $8 \%$ feedstocks, obtained from the mixing test $\left(160^{\circ} \mathrm{C}, 30 \mathrm{~min}\right.$ and $\left.30 \mathrm{rpm}\right)$.

Figure 10 illustrates the mixing behaviour of three different feedstocks with solid loadings of 40, 60 and $60 \%$, which are denoted as Co-WC, Fe-Ni 8\% and 316L stainless steel, respectively. The imposed mixing parameters were a rotor speed of $30 \mathrm{rpm}$, a temperature of $160{ }^{\circ} \mathrm{C}$ and $30 \mathrm{~min}$ of mixing time. Varying the solid loading caused variation in the torque level, indicating differences in the mixture viscosity values. The mixing torque of the Co-WC 
feedstock loaded at $40 \%$ was significantly higher in comparison to the constant torque level for both feedstocks loaded at $60 \%$, which led to higher viscosity. This might be due to the particle size distribution and the higher density of Co-WC, which would have increased the resistance on the rotor blades. Similarly, the low solid loading appearance apparently can be deceptive.

In the case of the Co-WC powder, the solid loading range tested was measured. It was found to below in comparison to that of the stainless steel and Fe-Ni powders (see table 4). These low values appear closely related to the packing ability of the powders, the particle shapes and sizes, the particle size distributions and the tendency of the powder to agglomerate.

Table 4. An analysis of the field mixing and the mixability limit of the feedstocks

\begin{tabular}{|c|c|c|}
\hline Feedstocks & Field mixing range tested $(\%)$ & Early not mixable (\%) \\
\hline 316L stainless steel & $40-64$ & 66 \\
\hline Co-WC & $40-44$ & 46 \\
\hline Fe-Ni $8 \%$ & $40-60$ & 62 \\
\hline
\end{tabular}

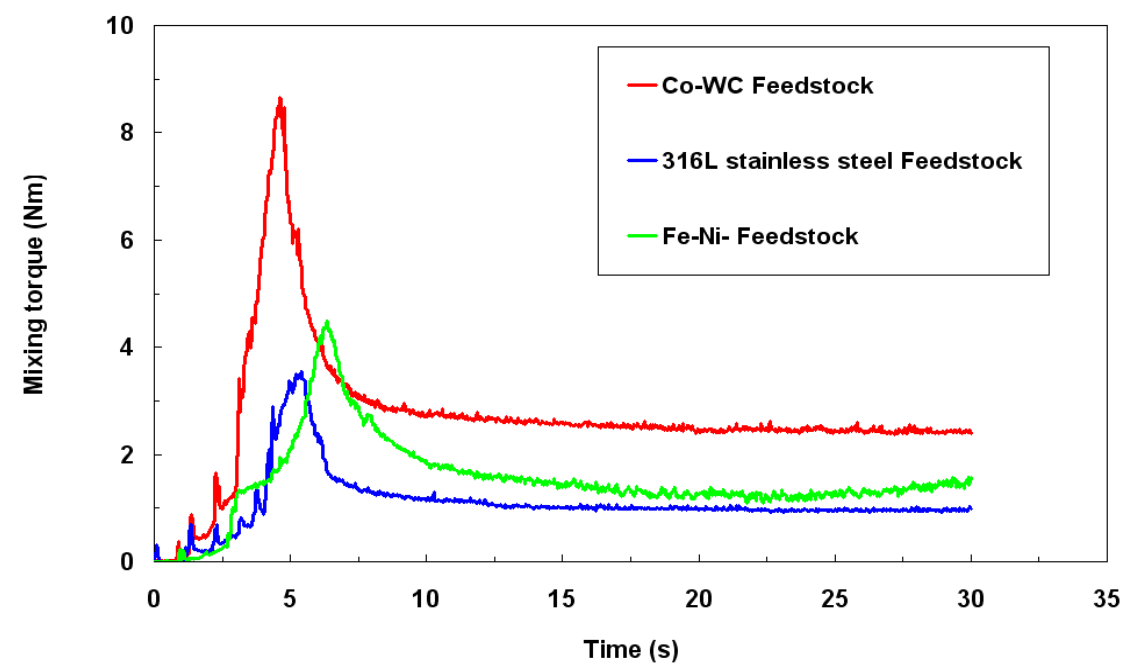

Figure 10. Mixing torque vs. time for three different feedstocks, carried out with a mixing test $\left(160{ }^{\circ} \mathrm{C}, 30 \mathrm{~min}\right.$ and $30 \mathrm{rpm}$ ), corresponding to a Co-WC feedstock, 316L stainless steel and a Fe-Ni feedstock and obtained at different solid loadings of $40 \%, 60 \%$ and $60 \%$, respectively.

Measurements of shear viscosity were performed on the feedstock mixtures at different temperatures with a two-channel capillary rheometer; different shear rates were considered with the same capillary die diameter $\varnothing=1 \mathrm{~mm}$ (Fig. 11). Viscosity is one of the important parameters in the evaluation of the rheological behaviour of the MIM feedstock. Figure 11 shows the apparent viscosity-shear rate curves of the extruded feedstock tested at different temperatures in the range of 150 to $190{ }^{\circ} \mathrm{C}$. It should be noted that the $316 \mathrm{~L}$ stainless steel feedstock was difficult to extrude at the lower temperature, corresponding to $130{ }^{\circ} \mathrm{C}$, which is very close to the melting temperature of the PP polymer.

The feedstock viscosity decreases with shear rate and temperature, indicating pseudoplastic flow behaviour and increases with high powder volume ratios. Normally, the exhibition of pseudo-plastic flow by the feedstock during moulding eases the mould filling process and minimises jetting defects [31] and [32]. As displayed in figure 11, the viscosity is temperature sensitive, decreasing with increasing temperature. This is attributed to the reduction in solid volume content, arising from increased binder expansion and destruction of the molecular chains during heating. From figure 11, it can be observed that the feedstock shows mouldability in the hot embossing process.

Figure 12 shows the shear viscosity of the different feedstocks versus the shear rate, which were developed and mixed under the same conditions and tested at $170{ }^{\circ} \mathrm{C}$. The results 
indicate that the three feedstocks possess pseudo-plastic rheological behaviour up to a shear rate of $10^{4} \mathrm{~s}^{-1}$. It was observed that the Co-WC feedstock exhibited viscosities higher than those of the other two feedstocks. This trend is the same as that observed for mixing torque.

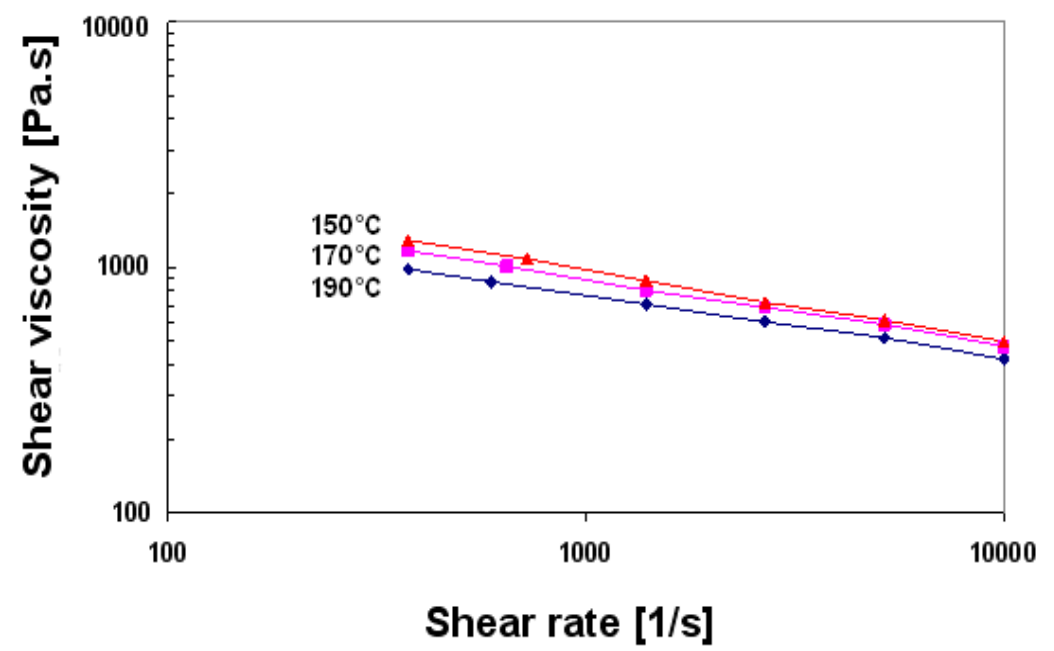

Figure 11. Viscosity of the 316L stainless steel feedstock with a solid loading of $60 \%$ by vol., tested at different temperatures.

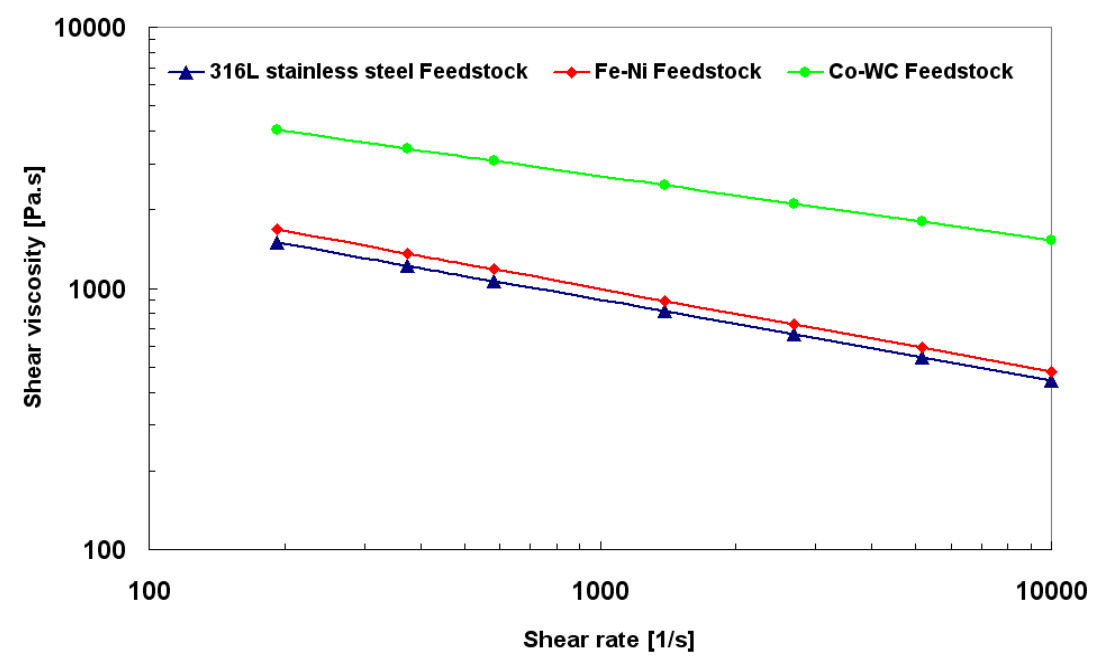

Figure 12. Viscosity of the three different feedstocks tested at $170^{\circ} \mathrm{C}$, corresponding to the Co-WC feedstock, 316L stainless steel and the Fe-Ni feedstock, analysed at different solid loadings of $44 \%, 60 \%$ and $60 \%$, respectively.

\subsection{HOT EMBOSSING TESTS}

\subsubsection{Influence of the embossing load}

In this portion of the investigation, the soft embossing process was conducted using the process mentioned above. Figure 13 relates typical results concerning the first experimental series. The feedstocks gradually filled the elastomeric mould cavities as the forming load was increased, followed by constant temperature and even during cooling of the cavities.

Thus for a properly defined forming temperature, by increasing the forming load of the feedstock substrate, one can help facilitate filling and is able to improve the surface roughness of the metallic replicas. Hence, the surfaces of the replicated parts were found to be smooth with $R_{a}<1 \mu \mathrm{m}$. This result can be partially related to the increased forming load, which is favourable for decreasing the surface roughness. 


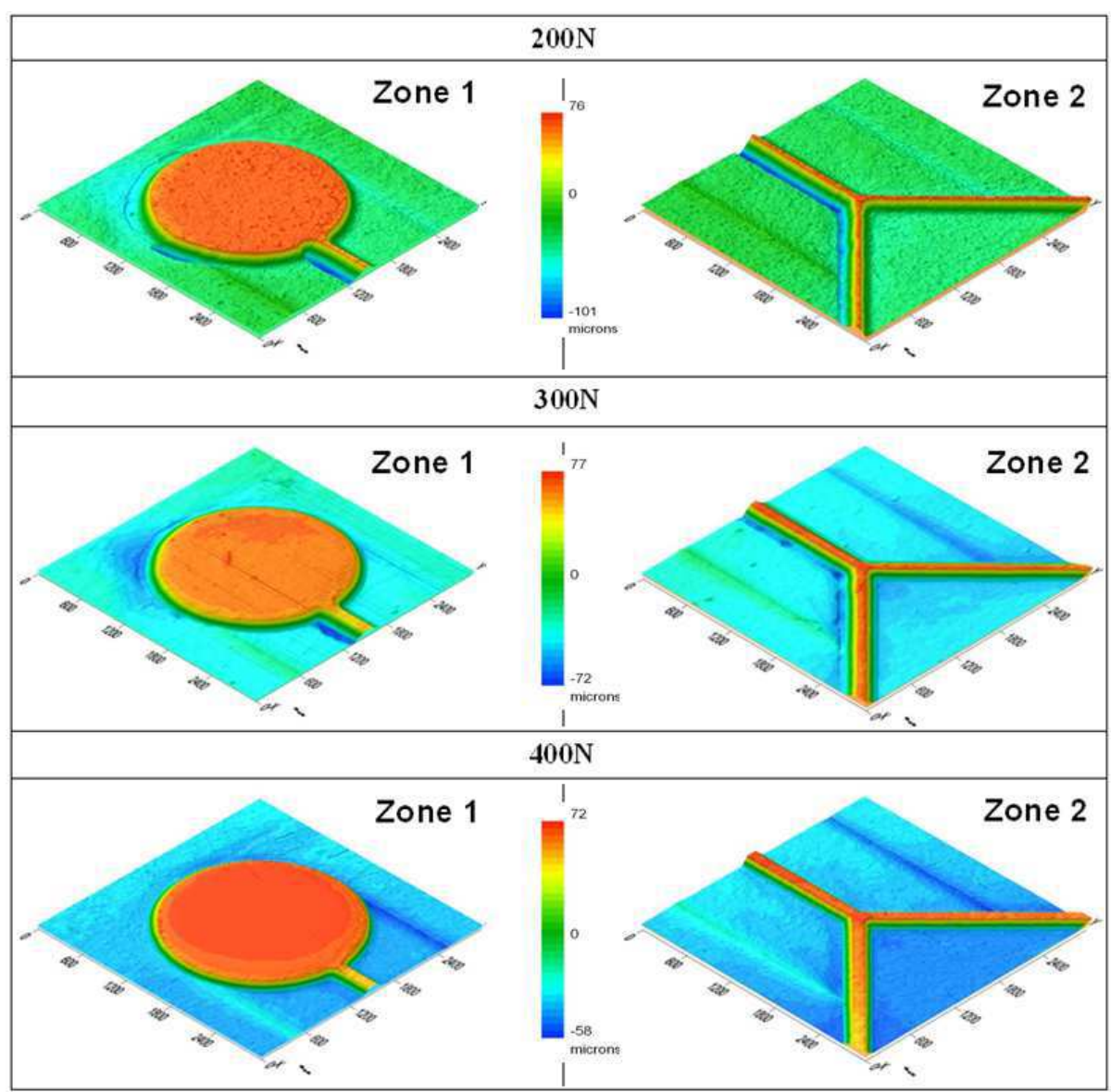

Figure 13. 3D topographic imprints of the Fe-Ni $8 \%$ feedstock replicas with a solid loading content of 62 vol. $\%$, obtained by the hot embossing process at different forming loads (unit: $\mu \mathrm{m}$ ).

\subsubsection{Influence of the hot embossing temperature}

In this portion of the investigation, the experimental procedure was conducted at different temperatures ranging from 130 to $190{ }^{\circ} \mathrm{C}$, and with the loading applied only once, the embossing temperature was reached. In this second series of experiments, the hot embossing process capability for the replication of purely metallic templates was also evaluated in terms of dimensional changes and the quality of pattern transfer. In Figures 14 and 15, each view corresponds to different stages in the formation of cavities and micro-channels. At $130{ }^{\circ} \mathrm{C}$, which is close to the melting temperature of PP, the surfaces of the embossed patterns were extremely rough, caused by partial melting of the binder system. However, it was found that the filling ratio increased with increasing forming temperature, yielding an accurate replica of the original imprint.

After several tests, it was found that the temperature strongly influenced the resulting filling rate and the final surface roughness of the cavities. This trend regarding the related effects can be directly observed in Figures $14 \mathrm{c}$ and $\mathrm{d}$. These experimental results are consistent with the results obtained from other positions of the same sample (see Figure 15c and $\mathrm{d}$ ). This could be due to the binder fluidity during hot embossing, which can affect the flow of the feedstock into the detail regions of the die mould. Therefore, at $190{ }^{\circ} \mathrm{C}$, the feedstocks may be pushed by the binders toward the mould details, leaving fewer defects in the final shape. The average surface roughness, $R_{a}$, measured at the base of the reservoirs decreased sharply at the melting temperature; then, the $\mathrm{R}_{\mathrm{a}}$ values levelled off at higher temperatures (beyond $170{ }^{\circ} \mathrm{C}$ ), see Fig. 16. 


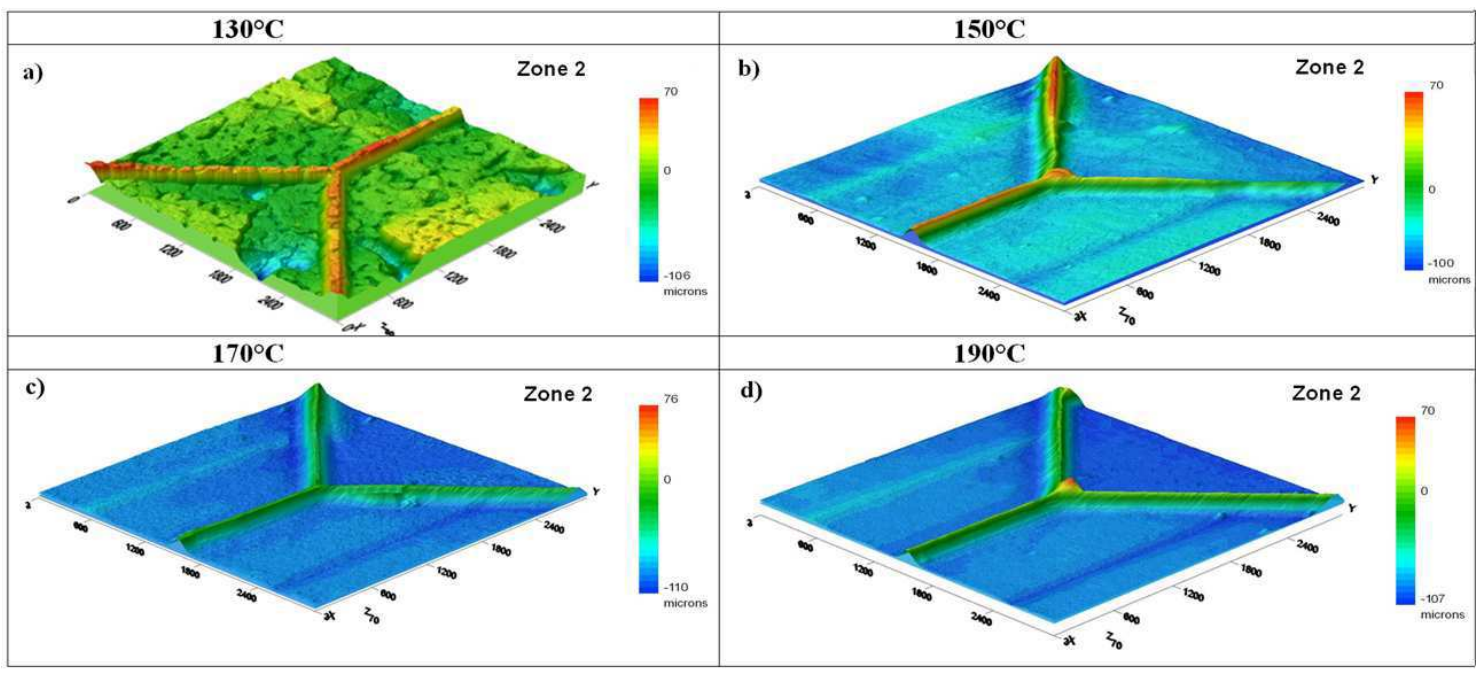

Figure 14. 3D topographic imprints of Co-WC replicas with a solid content of $44 \mathrm{vol}$. \%, obtained by the hot embossing process at different forming temperatures (unit: $\mu \mathrm{m}$ ).

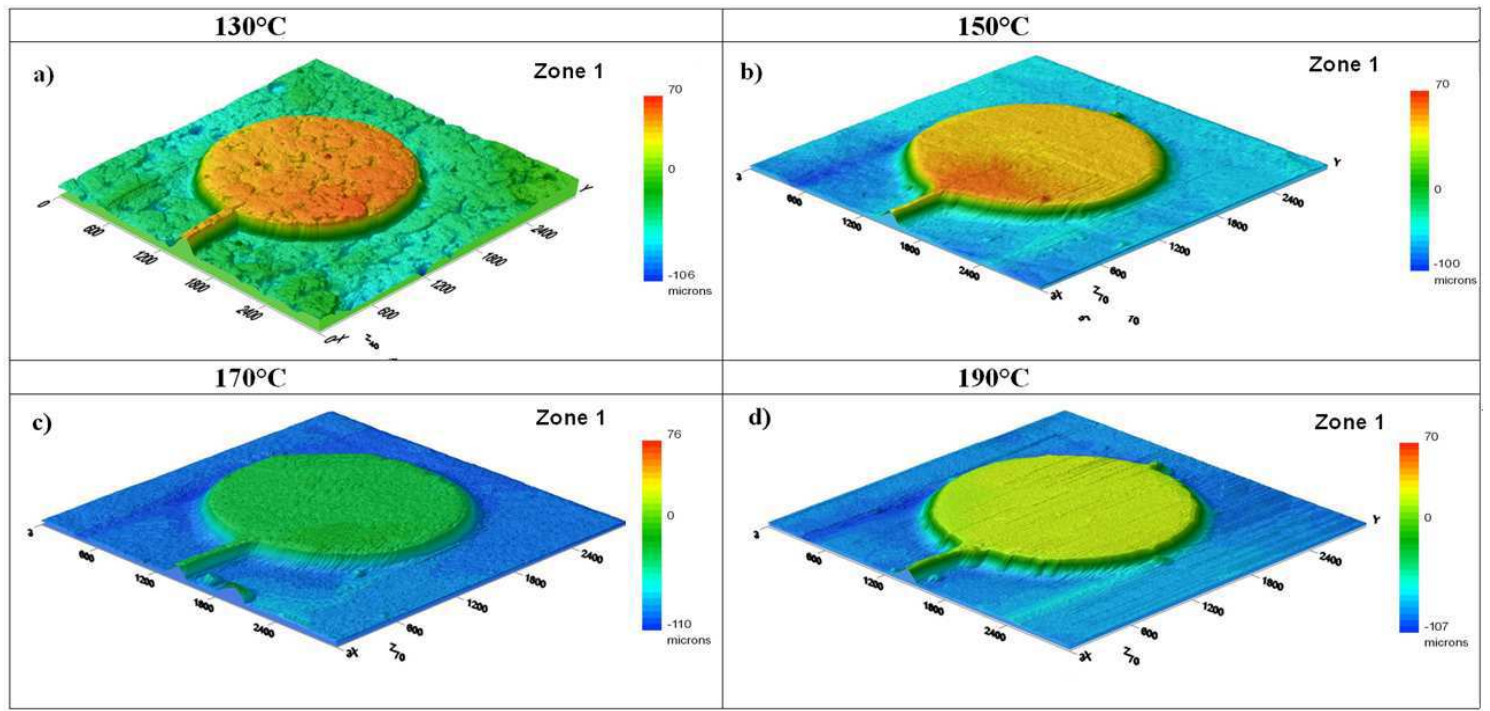

Figure 15. 3D topographic imprints of Co-WC replicas with a solid content of 44 vol. \%, obtained by the hot embossing process at different forming temperatures (unit: $\mu \mathrm{m}$ ).

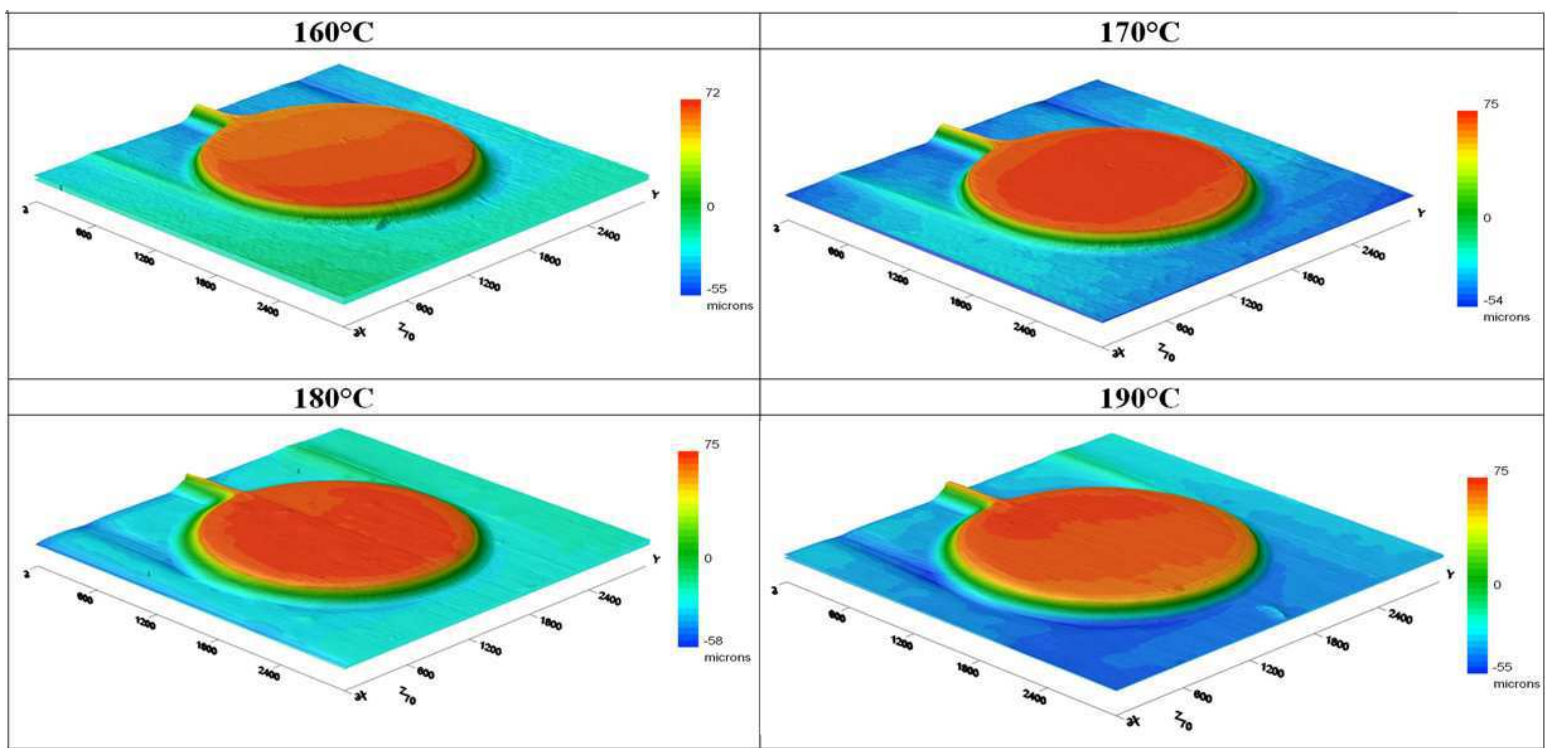

Figure 16. 3D topographic imprints of 316L stainless steel replicas with a solid content of 64 vol. \%, obtained by the hot embossing process at different forming temperatures (unit: $\mu \mathrm{m}$ ). 
Figure 17 shows the topographies of the metallic replicas fabricated with three different feedstocks. It is evident that the Co-WC feedstock replica was significantly rougher than that of the other feedstock replicas, most likely due to the feedstock viscosity. This trend is the same as that observed in the mixing torque and viscosity analyses. Hence, this result confirmed that the Co-WC feedstock with solid loadings from 42 to $44 \%$ was not feasible for hot embossing. At a $40 \%$ solid loading, the result is acceptable but is simply not sufficient to achieve fluid flow.

Thus far, the most uncomplicated method for decreasing the Co-WC feedstock viscosity is to lower the viscosity of the binder by increasing the forming temperature beyond $190{ }^{\circ} \mathrm{C}$. However, this is impractical because the binder begins to degrade at this temperature. The second possible solution is to develop a new formulation, one that is particularly well suited for this specific powder. The adopted final solution was to use the Co-WC feedstock with a solid loading of $38 \%$. This led to reduced feedstock viscosity and improvements in the filling ability and the surface quality of the replicas.

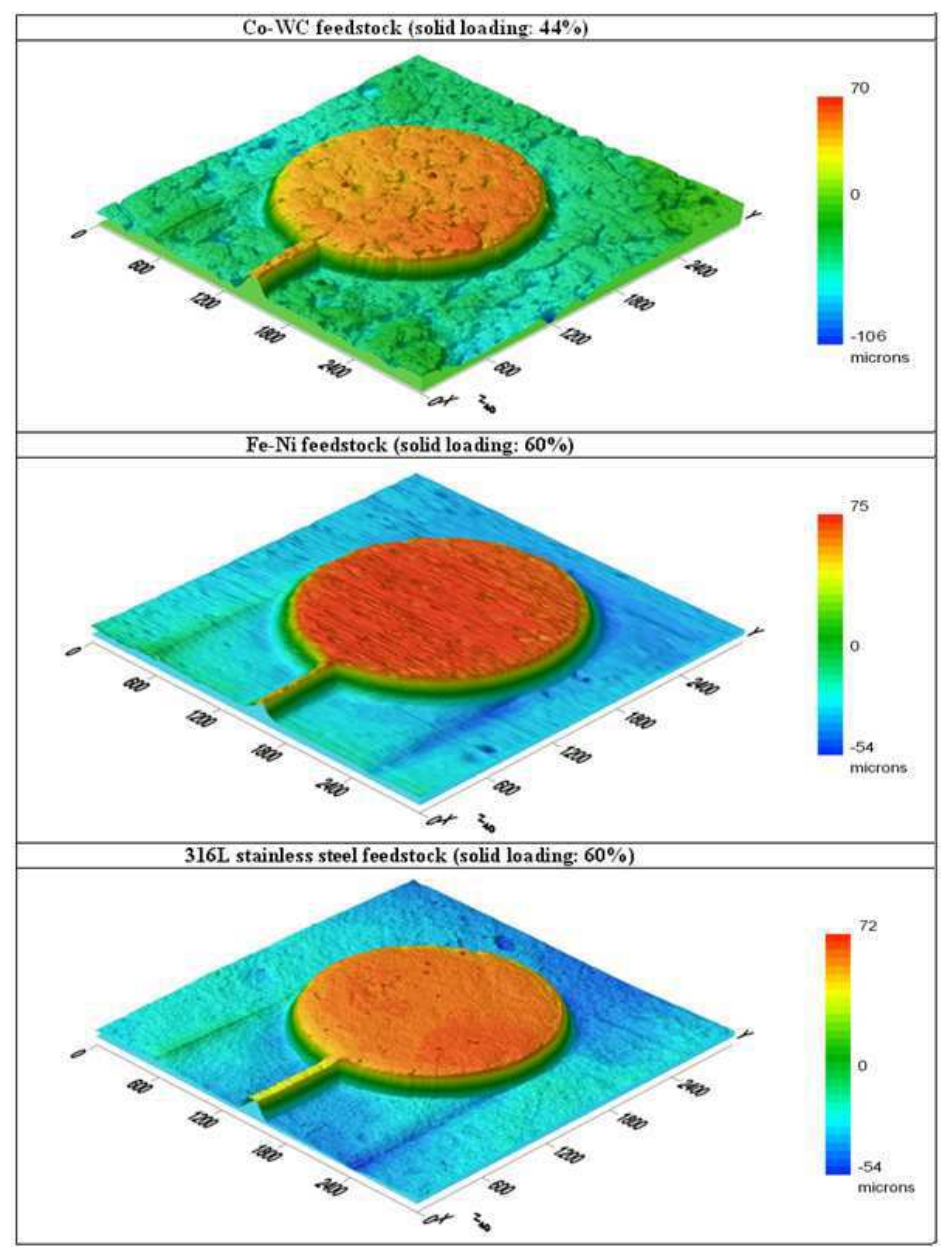

Figure 17. A comparison of 3D topographic imprints of the different metallic replicas, each obtained by the hot embossing process at a forming load and temperature of $400 \mathrm{~N}$ and $130{ }^{\circ} \mathrm{C}$, respectively (unit: $\mu \mathrm{m}$ )

As depicted in Figure 18, the feedstock gradually filled the mould cavities while the temperature was maintained in the loading stage. However, the feedstock was not able to completely fill the gap due to its low fluidity at $130{ }^{\circ} \mathrm{C}$ (see Figure $14 \mathrm{a}$ and $15 \mathrm{a}$ ) at the end of hot embossing process. Additionally, the profiles of the embossed replicas at $130{ }^{\circ} \mathrm{C}$ show defects, such as ridges in the top surface. At higher temperatures, filling is a quick process, and complete filling occurs when the hot embossing temperature exceeds $160^{\circ} \mathrm{C}$ (see Figure $14 \mathrm{c}$ and $15 \mathrm{c}$ ). These results show that high replication accuracy can be achieved using the proper forming temperature in the hot embossing process without vacuum. 
In Figure 18, the cast embossed replicas are compared to an elastomeric imprint. The scanning microscopy mechanical (SMM) profile relates the variation observed in these cases (the cross section shown is related to zone 1 in Figure 6b). Although a constant load was maintained until separation, and there was no apparent irregularity during the experiment, the SMM profiles indicate the presence of a distinct trace of the samples after embossing. It can be concluded that the forming load and temperature values determine the replication accuracy in terms of the width and shape and have significant influence on the accuracy of the final replication.

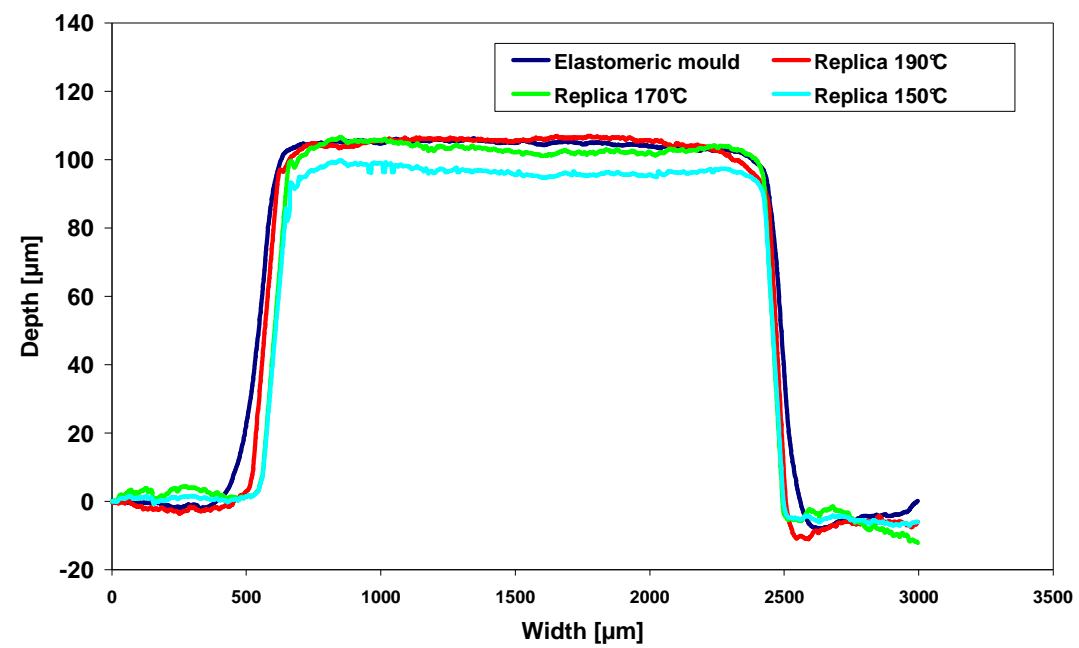

Figure 18. A comparison of the variations in the 2D topographical profiles of the elastomeric moulds and the FeNi $8 \%$ metallic replicas obtained by hot embossing at different temperature, along the $\mathrm{x}$-x direction (zone 1).

Fig. 19 shows the photograph of the micro-fluidic samples following the embossed processing step using the different sample types. The samples were obtained under the same conditions. Good shape retention without warpage or cracking was achieved following de-moulding.
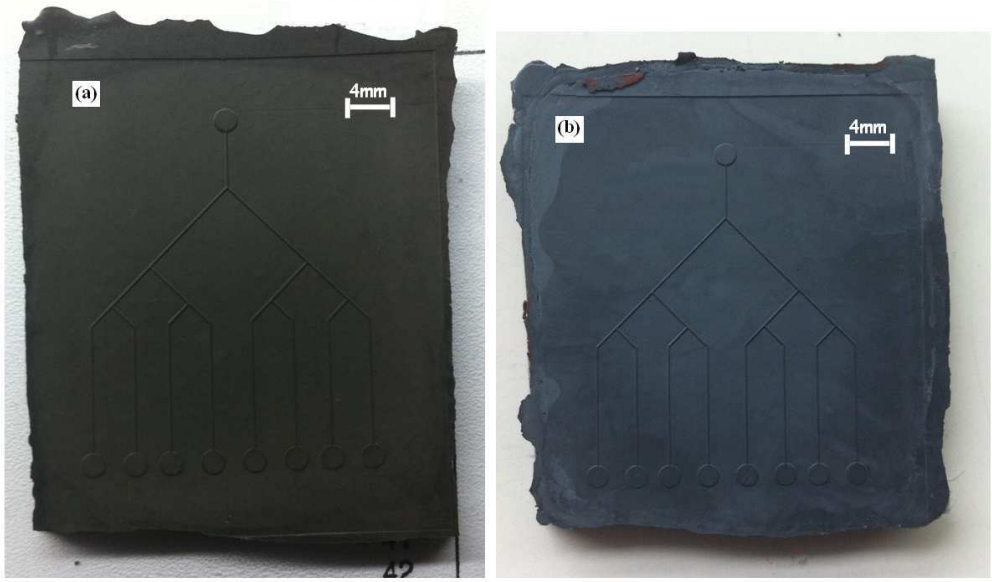

Figure 19. Photographs of the micro-fluidic samples after the embossing step using two different feedstocks for (a) Co-WC with the solid loading of $38 \%$ vol. and (b) Fe-Ni with the solid loading of $60 \%$ vol.

\subsection{DEBINDING AND SINTERING RESULTS}

As an example, the 316L stainless steel components shown in Figure 20 were obtained after debinding was started at room temperature and completed at $500{ }^{\circ} \mathrm{C}$ over the course of approximately $150 \mathrm{~min}$; following this step, the temperature was maintained for $30 \mathrm{~min}$. After, the components were heated to $1250{ }^{\circ} \mathrm{C}$ with a heating rate of $10^{\circ} \mathrm{C} / \mathrm{min}$ and then were held at a constant temperature for $60 \mathrm{~min}$. Finally, the cooling stage was carried out a rate of 
$10^{\circ} \mathrm{C} / \mathrm{min}$ for the components. As shown in Figure 20, the components were correctly sintered without the appearance of obvious defects or cracks near the interface. Figure 21 shows a photograph of the micro-fluidic components after undergoing different processing steps.

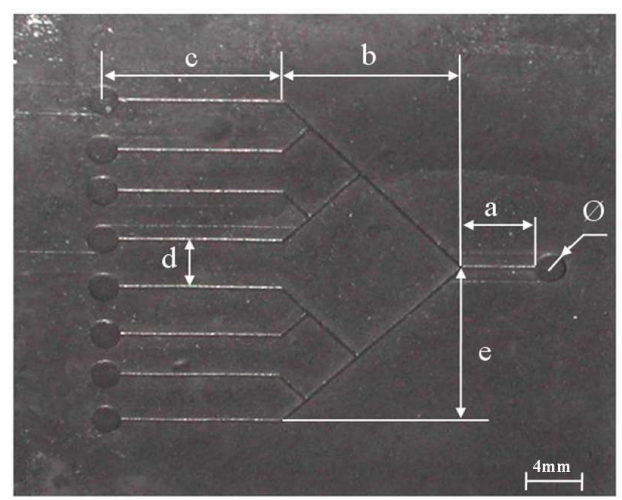

Figure 20. A photograph of the micro-fluidic system replica after the sintering stage (a solid loading equal to 60 $\%$ in vol. of $316 \mathrm{~L}$ stainless steel powders).
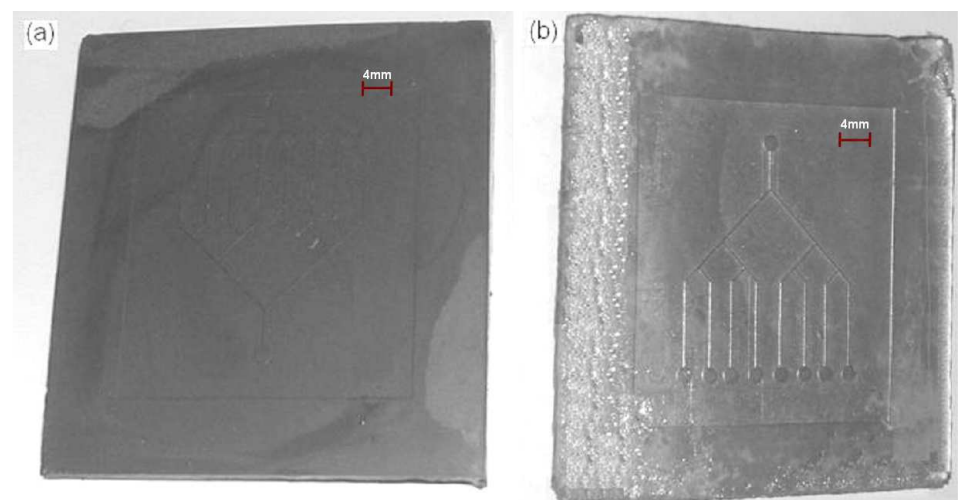

Figure 21. Photographs of the micro-fluidic tools after (a) the embossing and (b) sintering steps, produced using 316L stainless steel feedstocks (with a solid loading of $64 \%$ ).

As shown in Figure 22, the metallic replicas were approximately $10 \mu \mathrm{m}$ shallower than designed, which is likely due to shrinkage after the sintering step. In this stage, the component undergoes a low dimensional anisotropic shrinkage in the range of 10 to $14 \%$, depending on the powder characteristics, the solid loading, etc. This dimensional change occurred across the sample and can be compensated in the design of the mould cavity.

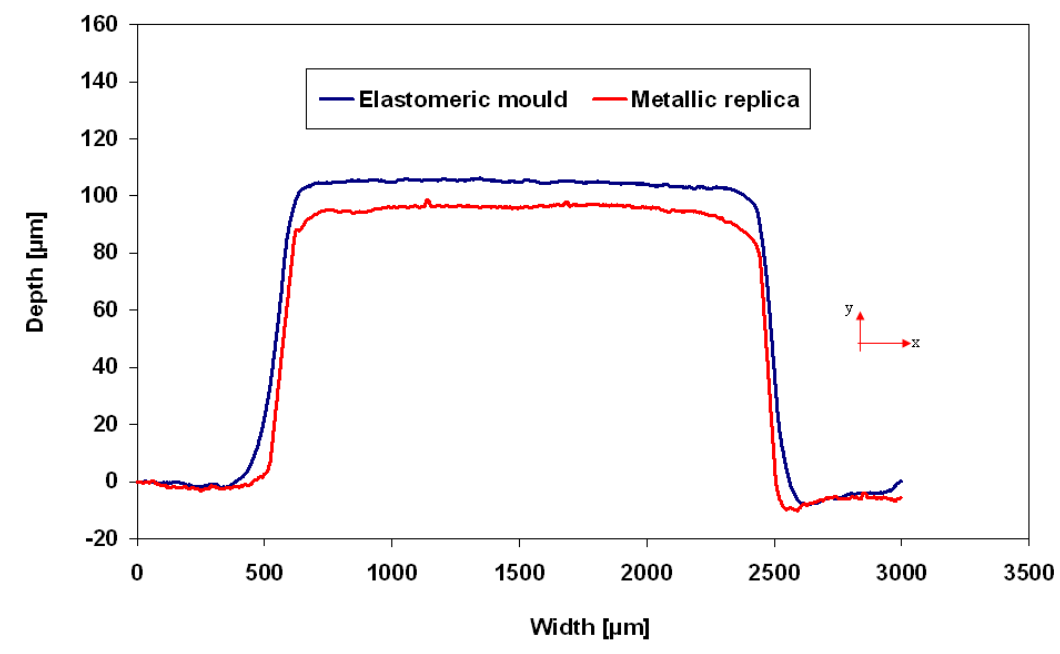

Figure 22. A comparison of variations in the $2 \mathrm{D}$ topographical profiles of the elastomeric moulds and the metallic replicas after the sintering stage using $316 \mathrm{~L}$ stainless steel feedstock (60\% vol.) and obtained by the hot embossing process, sampled along the $\mathrm{x}-\mathrm{x}$ direction (zone 1$)$. 
The dimensions of the micro-fluidic samples for three different solid loadings are given in Table 5. Compared with the silicon mould insert, the dimensional change after the sintering stage is clearly evident. The dimensional changes in the length and width of the microstructures showed similar trends. For example, in the Co-WC samples, the shrinkage values were approximately 21 and $24 \%$. However, the width and height of the embossed microstructures decreased gradually as the sintering temperature was increased, regardless of the powder used.

Table 5. Dimensions of the elastomeric mould and micro-sized structures of the micro-fluidic samples.

\begin{tabular}{|c|c|c|c|c|c|c|c|c|c|}
\hline \multirow{3}{*}{$\begin{array}{c}\text { Dimensions } \\
{[\mathrm{mm}]}\end{array}$} & \multirow{3}{*}{$\begin{array}{c}\text { Si } \\
\text { mould } \\
\text { insert }\end{array}$} & \multicolumn{8}{|c|}{ Micro-sized structure } \\
\hline & & \multicolumn{3}{|c|}{$\begin{array}{l}\text { 316L stainless steel } \\
1250{ }^{\circ} \mathrm{C}-10{ }^{\circ} \mathrm{C} / \mathrm{min}\end{array}$} & \multicolumn{3}{|c|}{$\begin{array}{c}\text { Fe-Ni } 8 \% \\
1200{ }^{\circ} \mathrm{C}-10{ }^{\circ} \mathrm{C} / \mathrm{min}\end{array}$} & \multicolumn{2}{|c|}{$\begin{array}{c}\text { Co-WC } \\
1000{ }^{\circ} \mathrm{C}-10{ }^{\circ} \mathrm{C} / \mathrm{min}\end{array}$} \\
\hline & & $60 \%$ & $62 \%$ & $64 \%$ & $56 \%$ & $58 \%$ & $60 \%$ & $38 \%$ & $40 \%$ \\
\hline$\varnothing$ & 2 & $1.60 \pm 0.01$ & $1.66 \pm 0.01$ & $1.72 \pm 0.01$ & $1.56 \pm 0.01$ & $1.64 \pm 0.01$ & $1.68 \pm 0.01$ & $1.52 \pm 0.1$ & $1.56 \pm 0.1$ \\
\hline $\mathbf{a}$ & 6 & $4.92 \pm 0.01$ & $5.04 \pm 0.01$ & $5.16 \pm 0.01$ & $4.74 \pm 0.01$ & $4.98 \pm 0.01$ & $5.04 \pm 0.01$ & $4.56 \pm 0.1$ & $4.74 \pm 0.1$ \\
\hline b & 14 & $11.34 \pm 0.01$ & $11.48 \pm 0.01$ & $11.90 \pm 0.01$ & $10.92 \pm 0.01$ & $11.34 \pm 0.01$ & $11.90 \pm 0.01$ & $10.78 \pm 0.1$ & $11.06 \pm 0.1$ \\
\hline c & 14 & $11.10 \pm 0.02$ & $11.62 \pm 0.02$ & $12.32 \pm 0.02$ & $10.78 \pm 0.02$ & $11.48 \pm 0.02$ & $11.76 \pm 0.02$ & $10.78 \pm 0.2$ & $11.20 \pm 0.2$ \\
\hline d & 4 & $3.24 \pm 0.01$ & $3.36 \pm 0.01$ & $3.48 \pm 0.01$ & $3.12 \pm 0.01$ & $3.28 \pm 0.01$ & $3.40 \pm 0.01$ & $3.04 \pm 0.1$ & $3.16 \pm 0.1$ \\
\hline e & 14 & $11.48 \pm 0.02$ & $11.62 \pm 0.02$ & $12.18 \pm 0.02$ & $11.06 \pm 0.02$ & $11.34 \pm 0.02$ & $11.76 \pm 0.02$ & $10.50 \pm 0.2$ & $10.92 \pm 0.2$ \\
\hline
\end{tabular}

Co-WC powders are usually sintered with a partial liquid phase at temperatures above $1280{ }^{\circ} \mathrm{C}$ to reduce the size of the pores, to improve the hardness and the density and to evolve the microstructure and grain size [33-35]. In our application, the sintering temperature choice was limited to temperatures between 900 and $1050{ }^{\circ} \mathrm{C}$, i.e., without the liquid phase. The presence of this phase causes deformation of the micro-fluidic structures; that is, they disappear with increasing temperature. The results show that the occurrence of the partial liquid phase is closely associated with the development of a deformed micro-fluidic structure.

\subsection{MICROSTRUCTUREEVOLUTION}

Figures 23 and 24 include the micrographs of polished sintered microstructures, collected under an optical microscope at different sintering temperatures. It can be observed that the number of pores and the pore size both decreased as the sintering temperature was increased. In Fig. 23, at the temperature of $1100{ }^{\circ} \mathrm{C}$, a considerable amount of porosity is present, and the pore structure is irregular, indicating that the part was not appropriately sintered. Following sintering at the temperature of $1200{ }^{\circ} \mathrm{C}$, the grain size became larger than that at the temperature of $1100{ }^{\circ} \mathrm{C}$, while the pore size became smaller. A higher sintering temperature of $1300{ }^{\circ} \mathrm{C}$ resulted in higher densification, smoother pore structures and smaller pore sizes. At $1350{ }^{\circ} \mathrm{C}$ and above, the microstructures became denser still, and fewer tiny pores were found. 

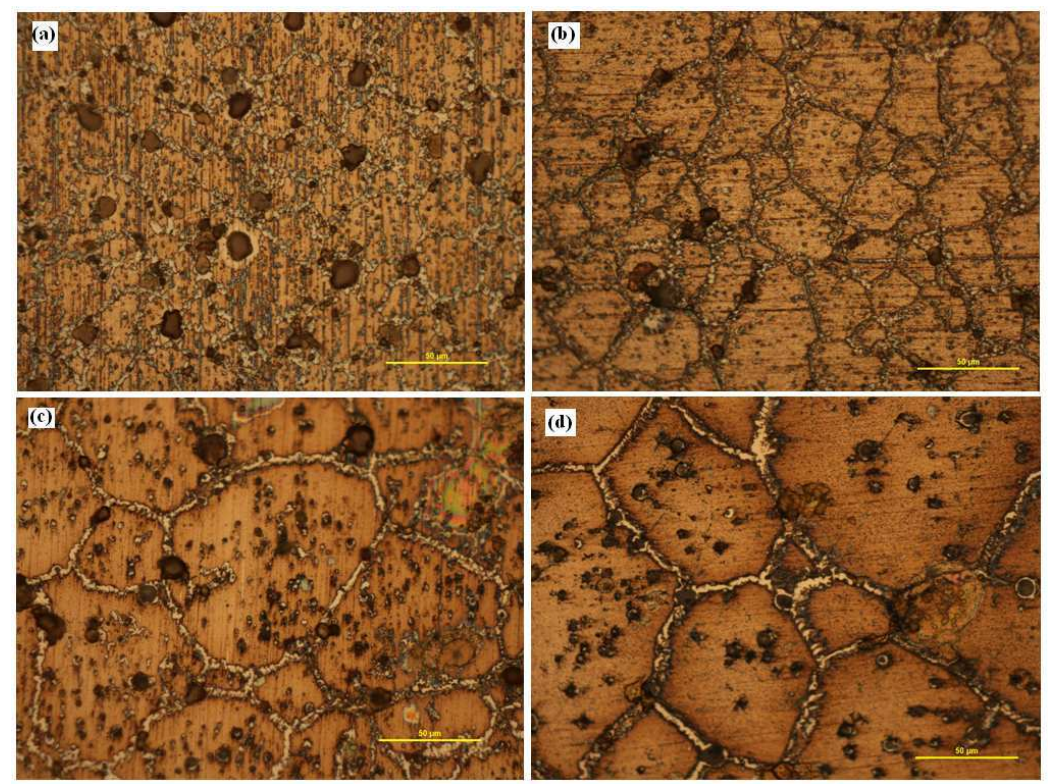

Figure 23. Optical micrographs of the sintered micro-structured stainless steel samples sintered at different temperatures: (a) $1100{ }^{\circ} \mathrm{C}$, (b) $1200{ }^{\circ} \mathrm{C}$, (c) $1300{ }^{\circ} \mathrm{C}$ and (d) $1360{ }^{\circ} \mathrm{C}$.
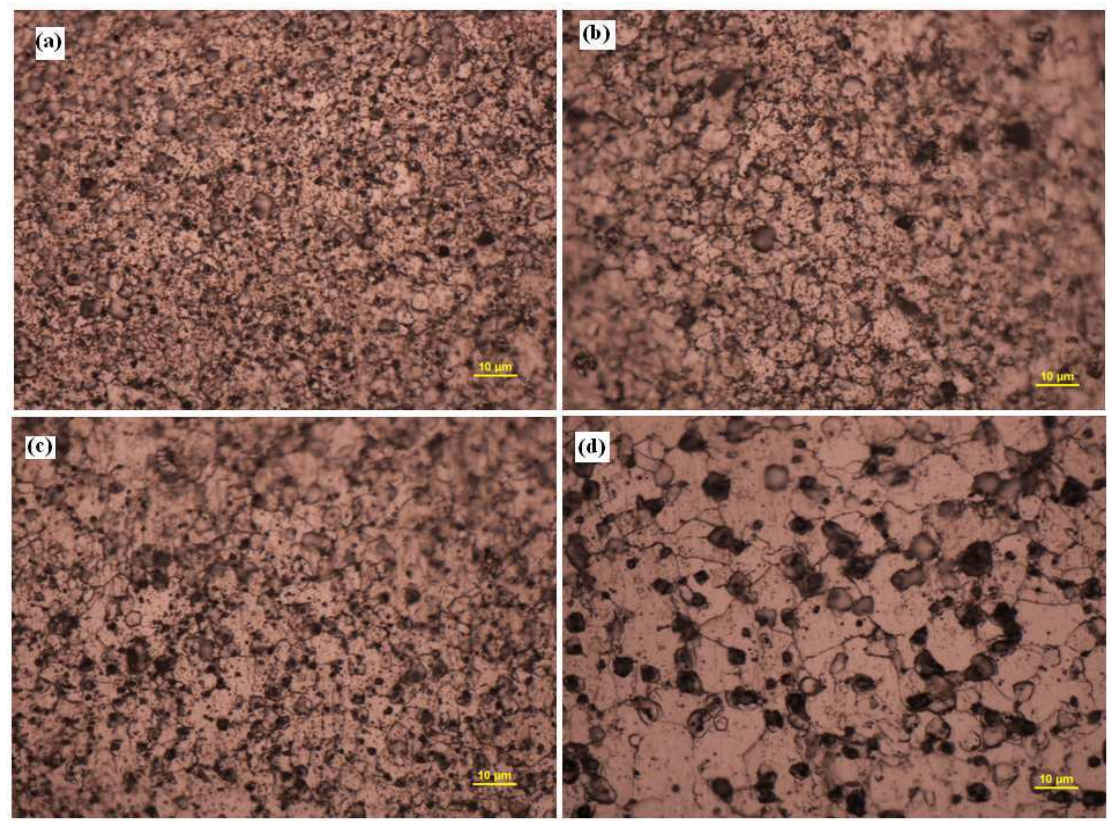

Figure 24. Optical micrographs of the sintered micro-structured stainless steel samples sintered at different temperatures: (a) $1150{ }^{\circ} \mathrm{C}$, (b) $1200{ }^{\circ} \mathrm{C}$, (c) $1250{ }^{\circ} \mathrm{C}$ and (d) $1300{ }^{\circ} \mathrm{C}$.

Following sintering, scanning electron micrographs were collected for two micro-fluidic replicas $(60 \%$ and $64 \%$ of $316 \mathrm{~L}$ stainless steel) without polishing. The specimens were observed in zone 2 (see Fig. 6), and the results are related in Figures 25 and 26. The grain sizes were dramatically increased following sintering. The porosity has almost entirely disappeared in the embossed specimen with a solid loading of $60 \%$, and the decrease in porosity in the specimen with a solid loading of $64 \%$ is clearly revealed, as well; this occurred as a result of the elimination of pores via grain boundary and volume diffusion at high temperatures [36]. 

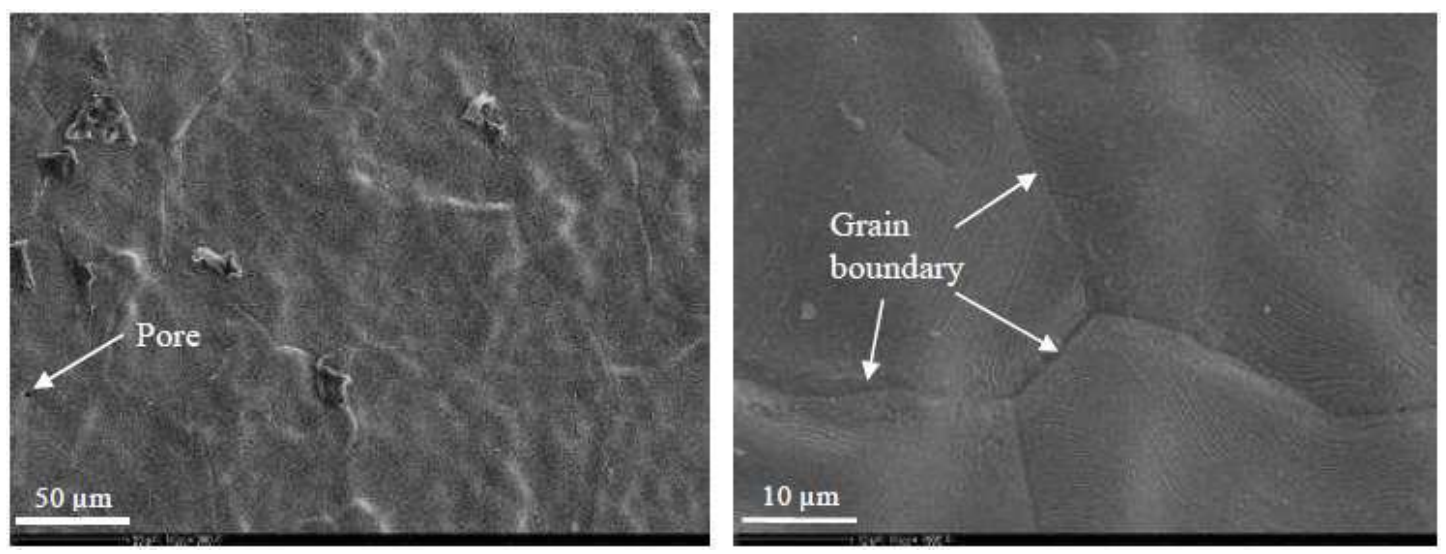

Figure 25. Scanning electron micrographs of the micro-fluidic specimens (embossed with a solid loading of 60 $\%$ ) before polishing.
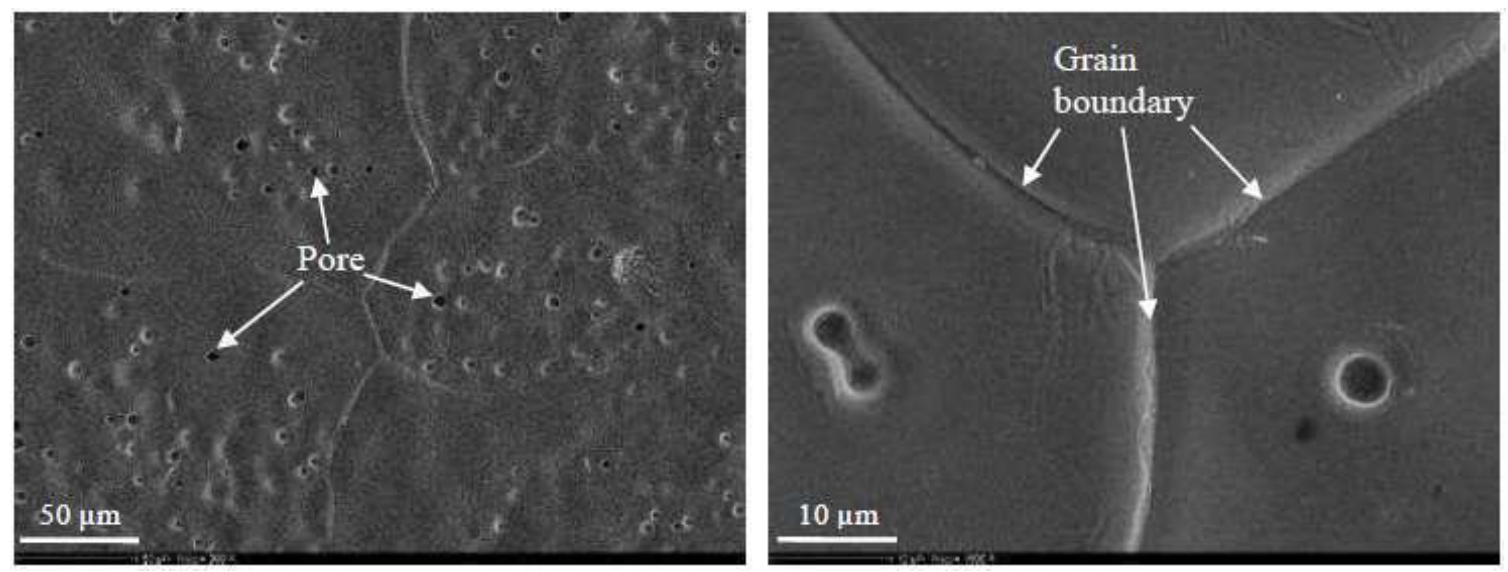

Figure 26. Scanning electron micrographs of the micro-fluidic specimens (embossed with a solid loading of 64 $\%$ ) before polishing.

\subsection{PHYSICAL PROPERTIES OF THE RESULTING MICRO-FLUIDIC REPLICAS 3.6.1. Shrinkage of the resulting micro-fluidic specimens}

The sizes and dimensions of the final components were measured and compared with the geometry of the embossed die mould to qualify the linear shrinkage with the respective sintering stage (see Fig. 27). The analyses of the dimensions were carried out on the sintered specimens embossed with the three feedstocks loaded at either $60-64 \%$ of 316L stainless steel, $40-44 \%$ of $\mathrm{Co}-\mathrm{WC}$ or $56-60 \%$ of Fe-Ni, respectively. The mean shrinkages are given in Table 6.

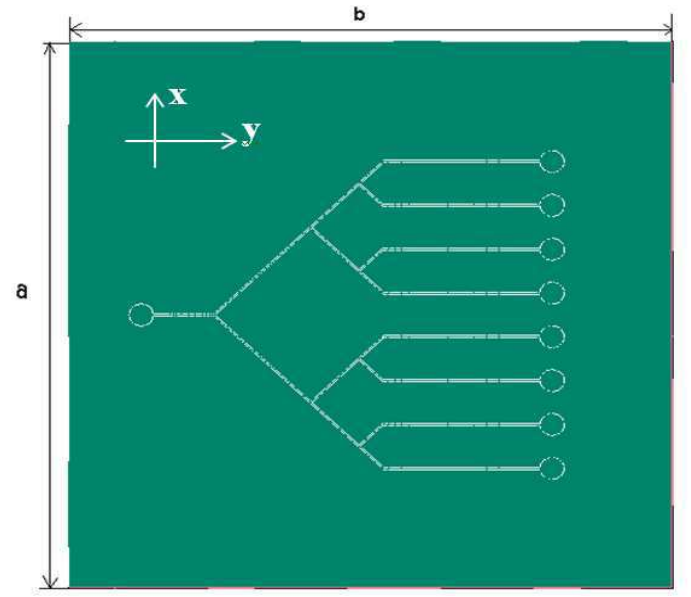

Figure 27. The top view of a section of localised dimensional measurements in the micro-fluidic simple. 
During the thermal debinding and sintering stages, an embossed sample undergoes binder elimination and subsequent particle bonding, resulting in dimensional changes in the samples. The overall shrinkage of cavities in the die mould after the sintering stage was found to be in the range from 10 to $20 \%$. The same phenomenon has been encountered by other authors, including Lohand et al. [37]. In comparison with the embossed mould insert, the width (a) and length (b) of the sintered samples decreased. As shown by the results related in Table 6, the sintering cycle with the heating rate of $10{ }^{\circ} \mathrm{C} / \mathrm{min}$ generated shrinkage in the Fe-Ni sample, totalling to $11.2 \%$ in the $\mathrm{y}-\mathrm{y}$ direction and $12.3 \%$ in the $\mathrm{x}-\mathrm{x}$ direction.

The main parameters affecting the final sample size already have been studied, and these include the metal powder morphology, the binder ingredients and proportions, the mixing conditions, the mould design, the embossing parameters, the rheological behaviour of the embossing materials, the debinding and sintering stages, the equipment and even the environmental conditions. Among these often integrally-related factors, the most sensitive are the solid loading and the mould design [37]. As shown, different degrees of shrinkage were revealed for the same directions in the micro-fluidic samples using the same solid loading. Because all of the conditions during the processing were also identical, these differences in our experimental results can be explained by the differences in the metal powder morphology between the 316L stainless and Fe-Ni powders.

Sintering of the micro-fluidic systems was studied as a function of heating rate. In regard to the three feedstocks, 316L stainless steels, Fe-Ni and Co-WC, the sintering cycle with the heating rate of $15{ }^{\circ} \mathrm{C} / \mathrm{min}$ tended to give the maximum shrinkage values, which were recorded as $9.7 \%, 10.7 \%$ and $13.1 \%$ in the y-y direction, respectively. It can be observed that a very high shrinkage in the $y-y$ direction was also revealed for the low feedstock loadings. This allowed for movement of the powder particles, leading to increased distortion.

Table 6. Linear shrinkage in the y-y direction corresponding to the micro-fluidic part (a sintering time of 60 $\min )$.

\begin{tabular}{|l|ccc|}
\hline Linear shrinkage & \multicolumn{3}{c|}{ Solid loading } \\
\hline
\end{tabular}

\begin{tabular}{|c|c|c|c|c|c|c|c|c|c|}
\hline & $60 \%$ & $62 \%$ & $64 \%$ & $56 \%$ & $58 \%$ & $60 \%$ & $38 \%$ & $40 \%$ & $42 \%$ \\
\hline Sintering temperature & \multicolumn{8}{|c|}{$1250{ }^{\circ} \mathrm{C}$} & \multicolumn{8}{|c|}{$1200{ }^{\circ} \mathrm{C}$} & \multicolumn{3}{|c|}{$1000{ }^{\circ} \mathrm{C}$} \\
\hline Heating rate [ $\left.{ }^{\circ} \mathbf{C} / \mathbf{m i n}\right]$ & \multicolumn{8}{|c|}{ Means value } \\
\hline $\mathbf{5}$ & 10.1 & 9.7 & 9.7 & 10.9 & 10.7 & 10.5 & 14.1 & 13.5 & 13.1 \\
\hline $\mathbf{1 0}$ & 9.9 & 9.6 & 9.8 & 11.2 & 10.7 & 10.6 & 14.3 & 13.7 & 13.2 \\
\hline $\mathbf{1 5}$ & 9.6 & 9.9 & 9.7 & 11.3 & 10.8 & 10.7 & 14.2 & 13.7 & 13.1 \\
\hline
\end{tabular}

\subsubsection{Densities of the resulting micro-fluidic specimens}

Additionally, the densities of the sintered micro-fluidic specimens were measured with the water displacement method (the Archimedes method) for each of the three feedstocks, and the resulting values are reported in Figures 28 and 29. The theoretical densities of the stainless

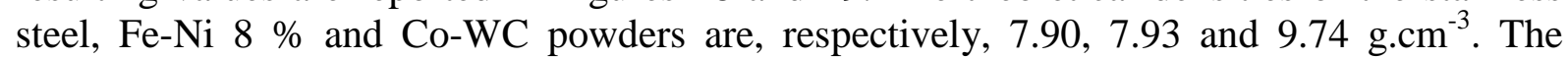
sintering temperature and solid loading both had a significant effect on the densification, i.e., the density increased significantly with increasing temperature and solid loading, as summarised in Fig. 28 and 29. The influence of sintering temperature on the densification of $316 \mathrm{~L}$ stainless steel was more pronounced in comparison with that of $\mathrm{Fe}-\mathrm{Ni}$; similarly, a significant densification change was identified when the tool steel softened at $1300{ }^{\circ} \mathrm{C}$. All experiments for the measurement of density in Co-WC cavity die moulds were obtained with a sintering temperature of 900 to $1050{ }^{\circ} \mathrm{C}$. The relative densities of the sintered micro-system samples were determined to be above $95 \%$ of the theoretical density of the three materials. 


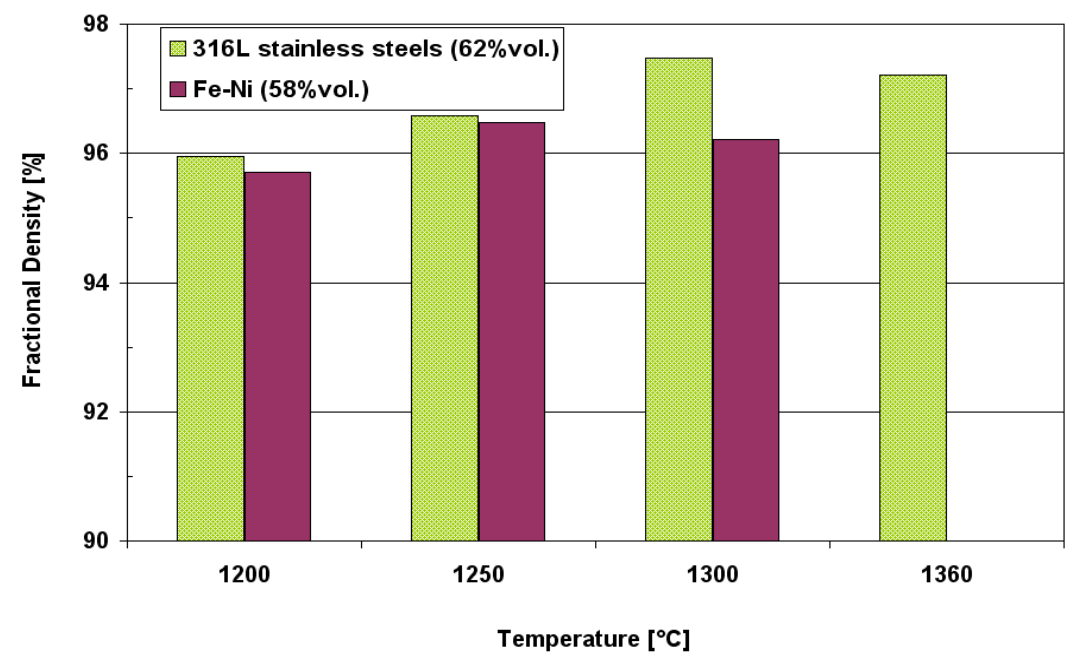

Figure 28. Effect of the sintering temperature on the sintered density (dwell time $60 \mathrm{~min}, 10{ }^{\circ} \mathrm{C} / \mathrm{min}$ ).

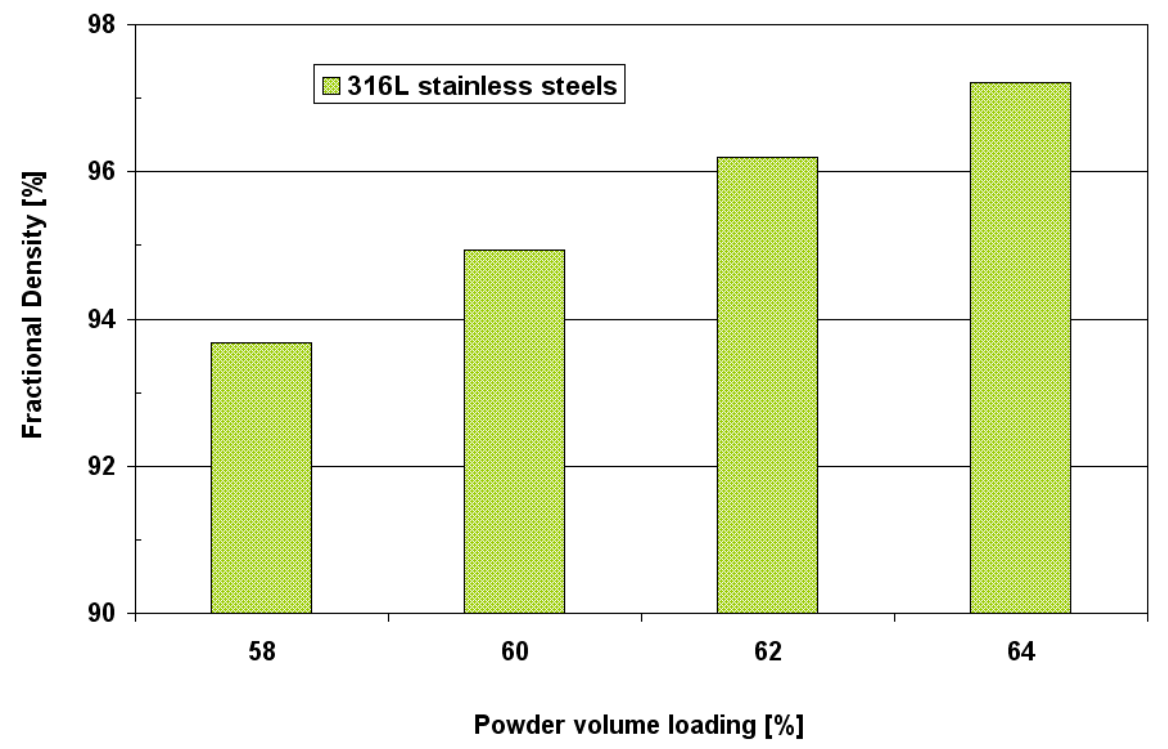

Figure 29. Effect of the solid loading on the sintered density (dwell time $60 \mathrm{~min}, 1250{ }^{\circ} \mathrm{C}$ ).

\subsubsection{Vickers hardness evolution of the micro-fluidic specimens}

After sintering the metallic die replicas, the specimens were subjected to hardness tests to assess and to qualify the mechanical property evolution versus the final sintering temperature. The hardness measurements were conducted on the polished sections of the different sintered components. Each area was polished using diamond pastes with $3 \mu \mathrm{m}$ and $0.1 \mu \mathrm{m}$ particle diameters at $150 \mathrm{rpm}$. Finally, the samples were polished again using a diamond paste of 0.1 $\mu \mathrm{m}$ for approximately $20 \mathrm{~s}$ and then were observed with an optical microscope. Fig. 30 demonstrates the variations in hardness for the micro-fluidic specimen as a function of the sintered temperature, as viewed from the top surface of the specimen. When the final sintering temperature was increased, the increase in density as the porosity is removed leads to an incremental increase in hardness. 


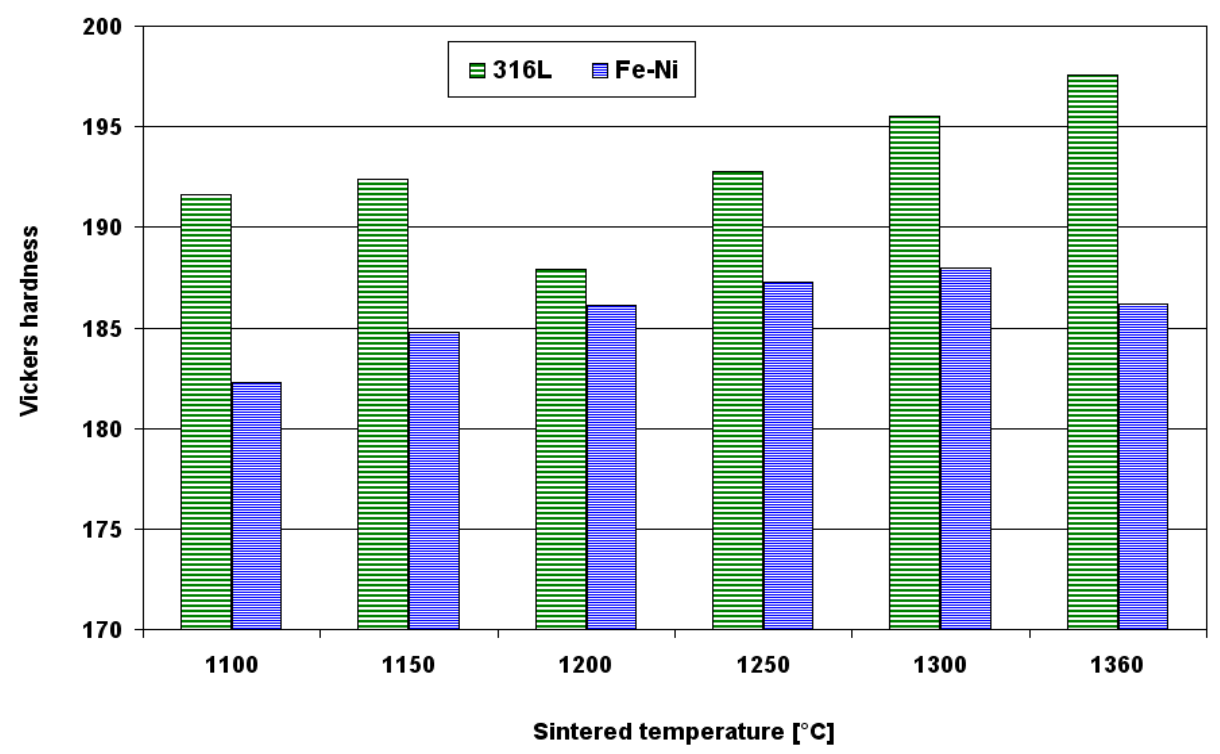

Figure 30. The variation in hardness as a function of the final sintering temperature.

For example, the Co-WC spherical fine powders present the highest hardness, attaining $1200 \mathrm{HV} 1$ at $1000{ }^{\circ} \mathrm{C}$, followed by Fe-Ni material $\left(188 \mathrm{HV} 1\right.$ at $\left.1250{ }^{\circ} \mathrm{C}\right)$ and $316 \mathrm{~L}(197 \mathrm{HV}$ 1 at $1360{ }^{\circ} \mathrm{C}$ ). The hardness can be increased with further improvements in the material density and the proper control of grain growth.

\subsubsection{Roughness variation of the micro-specimens}

The surface roughness variations of the die mould cavities sintered a temperature in zone 2 (see Figure 6b) are shown in Fig. 31. It can be observed that an increase in the final sintering temperature caused a slight increase in the surface roughness of the materials. This roughness variation can be improved by using ultra-fine powders, which result in a significantly increased surface finish in the final die mould and also result in a more complete fill, yielding significantly finer details.

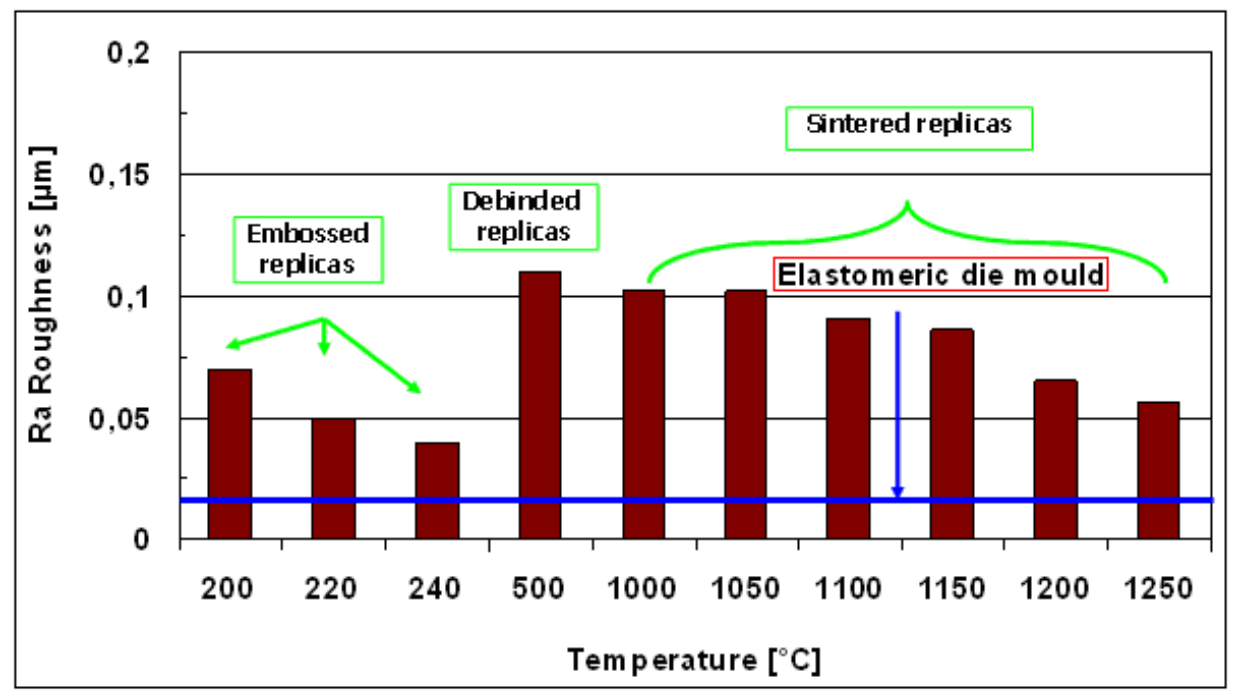

Figure 31. Surface roughness $\left(\mathrm{R}_{\mathrm{a}}\right)$ of the elastomeric mould inserts and the Fe-Ni micro-fluidic samples at different processing steps (a solid loading of $60 \%$ vol.).

Both mechanical and laser cutting are common fabricating processes used in today's manufacturing industries. Each method employs its own distinct equipment, and has its own 
advantages and disadvantages. As example, in milling operations, feed, cutting speed, cutting tool material, workpiece material, cutting tool geometry, vibrations and tool wear are some of the most important factors that affect the surface roughness of the mould machined [38, 39]. Several authors [40] and [41] argue that to prevent chatter and achieve good workpiece surface quality, the frequency of the cutting edge entering the cut during each rotation of the tool (tooth passing frequency) must differ from the natural and harmonic frequencies. The main weakness of the realisation of metallic mould inserts obtained by these process is the inability to obtain 3D shape variables of size less, and low roughness than, few microns from $0.1<\mathrm{Ra}<1 \mu \mathrm{m}$. It was also found that these traditional processes can also cause a loss of precision when going nanostructures or microstructures with large aspect ratio.

In this study, innovative solutions have been proposed and developed for manufacturing metallic tools to routinely reproduce a micro and nano-structured surface, with a lateral resolution less than $100 \mathrm{~nm}$, even near to $10 \mathrm{~nm}$ for feedstocks produces very low viscosity. The study feasibility and the ability to rapid manufacturing have been demonstrated, and this should be applicable in several various applications. However, it should be emphasized that, a decrease in the surface roughness may result in part from contributions to drive the flow characteristics of liquid in channels, because the surface effects are significant [42].

\section{Conclusions}

In the present analysis, the feasibility of hot embossing of micro-fluidic die mould cavities has been tested as 316L stainless steel, Fe-Ni $8 \%$ and WC-Co. The findings can be summarized as follows:

1) It has been shown that feedstock with solid loading in the range 40-64 vol. \%, 40-44 vol.\% and 40-60 vol.\%, for 316L stainless steel, WC-Co and Fe-Ni 8\%, respectively, are homogeneous and moldable through the feedstock homogeneity and rheological tests. However, feedstock with solid loading of 64,40 and 60 vol.\% were selected to be the better choice, as higher concentration of solid particles are preferred to limit shrinkage during debinding and sintering. Based on the thermogravimetric analysis and rheology measurements, the optimal mixing parameters were chosen to be a mixing temperature, mixing speed and mixing time of $160{ }^{\circ} \mathrm{C}, 30 \mathrm{rpm}$, and $30 \mathrm{~min}$, respectively.

2) In terms of rheological characteristics, different feedstocks are shear thinning fluids as viscosity decreases with increase in shear strain rate. In this case, the viscosity decreases with increasing temperature, but viscosity of the WC-Co feedstock is less sensitive to shear strain rate and temperature compared to that of the other feedstocks.

3) Based on the thermal characterisations of the feedstock, in one hand the feasibility of the feedstock for hot embossing of micro-fluidics die moulds was investigated, and in second hand, was also used to develop a suitable thermal treatment for both stages of the binder elimination process. The analysis of the hot embossing process for micro-structured metallic replicas demonstrated that the microstructure shapes were successfully embossed with the use of suitable forming parameters. These results confirm that the increasing temperature and pressure stage can determinate the replication accuracy by depth as well as the replication accuracy of the width and shape measurements. It was found that the replication accuracy strongly depends on the processing conditions. The results show also that microstructures can be successfully obtained, without visual debinding defects and the final sintered microstructures exhibit proper shape retention.

4) The dimension accuracy of the final die mould was mainly determined by geometrical dimension precision of embossing stage. In all processing parameters, the solid loading, 
the embossing temperature and the sintering temperature have the most important effects on the dimension precision and the material properties. The high powder loading allowed obtaining sintered parts with $96 \%$ of the theoretical densities.

\section{References}

[1] T. Gietzelt, O. Jacobi, V. Piotter, R. Ruprecht, J. Hausselt, Development of a micro annular gear pump by micro powder injection moulding, J. Mater. Sci.39 (2004) 2113-2119.

[2] G. Fu, N.H. Loh, S.B. Tor, Y. Murakoshi, R. Maeda, Replication of metal microstructures by micro powder injection moulding, Mater.Des. 25 (2004) 729-733.

[3] F. Benito-Lopez, S. Scarmagnani, Z. Walsh, B. Paull, M. Macka, D. Diamond, Spiropyran modified microfluidic chip channels as photonically controlled self-indicating system for metal ion accumulation and release, Sensor. Actua. 140 (2009) 295-303.

[4] D.F. Heaney, J.D. Gurosik, C. Binetj, Isotropic forming of porous structures via metal injection moulding, J. Mater. Sci. 40 (2005) 973-981.

[5] H. Zhang, X. He, X. Qu, L. Zhao, Microstructure and mechanical properties of high Nb containing TiAl alloy parts fabricated by metal injection molding, Mater Sci. Eng. A 526 (2009) 31-37.

[6] C. Karatas, A. Sozen, E. Arcaklioglu, S. Erguney, Investigation of mouldability for feedstocks used powder injection moulding, Mater.Des. 29 (2008) 1713-1724.

[7] R.M. McCormick, R.J. Nelson, M.G. Alonso-Amigo, D.J. Benvegnu, H.H. Hooper, Microchannel electrophoretic separations of DNA in injection-molded plastic substrates, Anal. Chem. 69 (1997) 26262630.

[8] Y.-J. Juang, L. L. James, Hot embossing in microfabrication. I. Experimental. Polym. Eng. Sci. 42 (2002) 539-550.

[9] Y. -J. Juang, L. L. James, Hot embossing in microfabrication. II. Rheological characterization and process analysis. Polym. Eng. Sci. 42 (2002) 539-550.

[10]L. Martynova, L.E. Locascio, M. Gaitan, G.W. Kramer, R.G. Christensen, W.A. Mac-Crehan, Fabrication of plastic microfluid channels by imprinting methods, Anal. Chem. 69 (1997) 4783-4789.

[11]S. Lan, H.J. Lee, E.H. Kim, J. Ni, S.H. Lee, X. Lai, J.H. Song, N.K. Lee, M.G. Lee, A parameter study on the micro hot-embossing process of glassy polymer for pattern replication, Microelectron. Eng. 86 (2009) 2369-3237.

[12]R. K. Jean, C. Y. Yue, Y. C. Lam, Z. Y. Wang, High fidelity hot-embossing of COC microdevices using a one-step process without pre-annealing of polymer substrate, Sensors and Actuators B 150 (2010) 692-699.

[13]R.D. Chien, Hot embossing of microfluidic platform, Heat Mass Transf. 33 (2006) 645-653.

[14]PV. Muterlle, M. Zendron, M. Perina, R. Bardini, A. Molinari, Microstructure and tensile properties of metal injection moulding Co-29Cr-6Mo-0.23C alloy, J. Mater.Sci.14 (2010) 1091-1099.

[15]M. Heckele, W. Bacher and K.D. Müller, Hot embossing - the molding technique for plastic microstructures, Microsyst. Tech. 4 (1998) 122-124.

[16]M. Sahli, C. Millot, C. Roques-Carmes, C. Khan Malek, J-C. Gelin, T. Barrière, Quality assessment of polymer replication by hot embossing and micro-injection moulding processes using Scanning Mechanical Microscopy, J. Mater.Process. Tech.209 (2009) 5851-5861.

[17]YH. Guu,MTK. Hou, Effect of machining parameters on surface textures in EDM of Fe-Mn-Al alloy, Mater.Sci.Eng. 466 (2007) 61-67.

[18] J. Recha, YC. Yen, MJ. Schaff, H. Hamdi, T. Altan, KD. Bouzakis, Influence of cutting edge radius on the wear resistance of PM-HSS milling inserts, Wear259 (2005) 1168-1176.

[19]F. Klocke, H. Kratz, Advanced tool edge geometry for high precision hard turning, Annals CIRP 48 (2005) 59-62.

[20] Y.K. Chou, H. Song, Tool nose radius effects on finish hard turning, Journal of Materials Processing Technology 148 (2004) 259-268.

[21]CA. Griffiths, SS. Dimov, EB. Brousseau, RT. Hoyle, The effects of tool surface quality in micro injection moulding, J.Mater.Process.Tech. 189 (2007) 418-427.

[22]RM. German, EJ. Westcot, C. Binet, In situ dimensional change, mass loss and mechanisms for solvent debinding of powder injection moulded components, Inter.J.Powder. Metall. 46 (2003) 61-67.

[23] L. Liu, NH. Loh, BY. Tay, SB. Tor, Y. Murakoshi, R. Maeda, Mixing and characterisation of 316L stainless steel feedstock for micro powder injection moulding, Mater.Charac. 54 (2005) 230-238.

[24]BY. Tay, NH. Loh, SB. Tor, FL. Ng, G. Fu, XH. Lu, Characterisation of micro gears produced by micro powder injection moulding, Powder Tech. 188 (2009) 179-182.

[25] J. Meng, NH. Loh, G. Fu, SB. Tor, BY. Tay, Replication and characterization of 316L stainless steel micromixer by micro powder injection moulding, J.Alloys Comp. 496 (2010) 293-299.

[26] G. Fu, SB. Tor, NH. Loh, DE. Hardt, Micro-hot-embossing of 316L stainless steel micro-structures, Appl. Phys. 97 (2009) 925-931. 
[27]JS. Kim,K. Jiang, I. Chang, Pressure Free Fabrication of 3D Micro-components Using Al Powder, Adv. Eng. Mater. 8 (2006) 38-41.

[28] M. Imbaby, K. Jiang, I. Chang, Fabrication of 316-L stainless steel micro parts by softlithography and powder metallurgy, Mater. Lett. 62 (2008) 4213-4216.

[29]D. Zhang, B. Su, TW. Button, Micro-fabrication of three-dimensional, free-standing ceramic MEMS components by soft moulding, Adv. Eng. Mater. 5 (2003) 924-927.

[30]Z. Zhu, X. Wei, K. Jiang, A net-shape fabrication process of alumina micro-components using a soft lithography technique, J. Micromech. Microeng. 17 (2007) 193-198.

[31]RM. German,A. Bose, Injection molding of metals and ceramics. Metal Powder Industries Federation; 1997.

[32] KN. Hunt, JRG. Evans, J. Woodthorpe, The influence of mixing route on the properties of ceramics injection molding blends, Br Ceram. Trans. 87 (1988) 17-21.

[33]J. Sun, F. Zhang, J. Shen, Characterizations of ball-milled nanocrystalline WC-Co composite powders and subsequently rapid hot pressing sintered cermets, Mater. Lett. 57 (2003) 3140-3148.

[34]D. Sivaprahasam, SB. Chandrasekar, R. Sundaresan, Microstructure and mechanical properties of nanocrystalline WC-12Co consolidated by spark plasma sintering, Int. J. Refr. Met.hard Mater.25 (2007) 144-152.

[35]SH. Choi, SD. Kang, YS. Kwon, SG. Lim, KK. Cho,IS. Ahn, The effect of sintering conditions on the properties of WC-10wt\%Co PIM compacts, Research Chem. Inter. 36 (2010) 743-748.

[36] RP. Koseski, P. Suri, NB. Earhardt, RM. German, YS. Kwon, Micro-structural evolution of injection molded gas- and water-atomized 316L stainless steel powder during sintering, Mater.Sci.Eng. A 309 (2005) 171-177.

[37]NH. Lohand RM. German, Statistical analysis of shrinkage variation for powder injection moulding, J.Mater.ProcessTech. 59 (1996) 278-284.

[38]H. Paris, G. Peigne, R. Mayer, Surface shape prediction in high speed milling, International Journal of Machine Tools \& Manufacture, 44 (2004) 1567-1576.

[39]Z. Houming, W. Chengyong, Z. Zhenyu, Dynamic characteristics of conjunction of lengthened shrink-fit holder and cutting tool in high-speed milling, Journal of Materials Processing Technology, 207 (2008) 154162.

[40]U. Şeker, İ. Çiftçi, H. Hasirci, The effect of alloying elements on surface roughness and cutting forces during machining of ductile iron, Materials and Design, 24 (2003) 47-51.

[41]A.K. Ghani, I.A. Choudhury, Husni, Study of tool life, surface roughness and vibration in machining nodular cast iron with ceramic tool, Journal of Materials Processing Technology, 127 (1) (2002) 17-22.

[42]B. Zhao, J.S. Moore, D.J. Beebe, Surface-directed liquid flow inside microchannels, Science, 291 (2001) 1023-1026 